\title{
Inter-Laboratory Validation of a Thin Film Microextraction Technique for Determination of Pesticides in Surface
}

\section{Water Samples}

Hamed Piri-Moghadam¹, Emanuela Gionfriddo ${ }^{1}$, Angel Rodriguez-Lafuente ${ }^{2}$, Jonathan J Grandy ${ }^{1}$, Heather L. Lord ${ }^{2}$, Terry Obal ${ }^{2}$, Janusz Pawliszyn*,1

1. Department of Chemistry, University of Waterloo, 200 University Avenue West, Waterloo, Ontario N2L 3G1, Canada

2. Maxxam Analytics, 6740 Campobello Road, Mississauga, Ontario L5N 2L8, Canada

\author{
*Corresponding author \\ Phone number: 1-519-888-4567 ext. 84641 \\ Fax: 1-519-746-0435 \\ E-mail: janusz@uwaterloo.ca (Janusz Pawliszyn)
}




\section{Abstract}

The primary goal of the present study is the inter-laboratory evaluation of a thin film microextraction (TFME) technique to be used as an alternative approach to liquid-liquid extraction (LLE). Polydimethylsiloxane/divinylbenzene (PDMS/DVB) and PDMS/DVBcarbon mesh supported membranes were used for the extraction of 23 targeted pesticides, while a thermal desorption unit (TDU) was employed to transfer these analytes to a GC/MS instrument for separation and detection. After optimization of the most critical parameters, both membranes were capable of achieving limits of detection (LOD) in the low ng $\mathrm{L}^{-1}$ range while demonstrating excellent robustness, withstanding up to 100 extractions/desorption cycles. Furthermore, limits of quantification (LOQ) between 0.025-0.50 $\mu \mathrm{g} \mathrm{L}^{-1}$ were achieved for the 23 compounds selected from several classes of pesticides with a wide range of polarities. A wide linear range of $0.025-10.0 \mu g \mathrm{~L}^{-1}$ with strong correlation to response $\left(\mathrm{R}^{2}>0.99\right)$ was attained for most of the studied analytes. Both membranes showed good accuracy and repeatability at three levels of concentration. Moreover, the method was also validated through blind split analyses of 18 surface water samples, collected within 3 months, using TFME at the University of Waterloo and LLE at Maxxam Analytics (Mississauga, ON) which is an accredited commercial analytical laboratory. Good agreement between the two methods was achieved with accuracy values ranging from $70-130 \%$, for the majority of analytes in the samples collected. At the concentration levels investigated, $90 \%$ of the analytes were quantifiable by TFME, whereas only 53\% of the compounds were reportable using the LLE method particularly at concentrations lower than $1 \mu \mathrm{g} \mathrm{L}^{-1}$. The comparison of TFME and LLE from several analytical aspects demonstrated that the novel TFME method gave similar accuracy to LLE, while providing additional advantages 
including higher sensitivity, lower sample volume, thus reduced waste production, and faster analytical throughput. Given the sensitivity, simplicity, low cost, accuracy, greenness and relatively fast procedure of TFME, it shows great potential for adoption in analytical laboratories as an alternative to LLE.

Keywords: Thin film microextraction, Liquid liquid extraction, Pesticides, Surface water, Inter-laboratory validation, Trace analysis 


\section{Introduction}

Quality-control of public drinking water is one the priorities of government environmental agencies due to the increase of environmental pollutants, such as pesticides, in surface water as a result of the extensive usage of pesticides in agriculture [1-3]. Several potential health effects such as damage to the eyes, liver, kidneys and spleen, anemia and increased risk of cancer derive from long-term exposure to pesticides above the maximum contaminant levels (MCL) [4,5]. Determination of pesticides in water samples at low and sub $\mu g \mathrm{~L}^{-1}$ levels is therefore necessary to meet the requirement of United States Environmental Protection Agency (US EPA) [6]. Among the sample preparation techniques used for extraction, enrichment and clean-up of pesticides from water samples, Liquid-liquid extraction (LLE) and solid phase extraction (SPE) represent two well-established techniques, widely employed as official methods of the US EPA [7]. LLE is a widely accepted method for routine analysis of drinking water samples in accredited contract analytical laboratories as it is an accurate technique and does not require any special apparatus. However, LLE is generally considered as a time-consuming and laborious technique, requiring large amounts of expensive and toxic organic solvents. SPE is a sample preparation technique poised to replace LLE as it requires small amount of organic solvent [8]. On the other hand, apart from difficulties in automation, filtering the suspended solids and particulate prior to the SPE procedure may result in loss of target compounds which may be difficult to account for in a supposedly exhaustive technique.

As an alternative to these aforementioned exhaustive methods, solid phase microextraction (SPME), which was introduced by Pawliszyn et al., is a well-known, solvent-less sample preparation technique capable of performing extraction, pre-concentration and sample clean-up in a single step[9]. There are several geometries of SPME including fiber[10,11], coated-tip (miniaturized fiber)[12], in-tube[13][14] and membrane 
(blade and fabric support)[15,16] that makes it a robust technique for convenient coupling to different analytical instruments[12,13,16-25]. Furthermore, SPME has been widely used for several applications including water sampling and analysis [10,21,26], food analysis [27-29], biofluids, in-vivo and non-destructive analysis [30,31], metabolomics [25,32] and tissues sampling [23,33], among many others. Unlike LLE and SPE techniques, SPME is a non-exhaustive sample preparation method [34,35] for which quantitation may be performed by use of several different calibration methods chosen in accordance to the conditions, limitations, complexity of the matrix and goal of study [36]. It is worth noting that there are already some official methods which employ the SPME fiber, published by several agencies including US EPA [37], International Standard Organization (ISO) [38,39] and American Standards for Testing of Materials (ASTM) [40-43]. In addition to the aforementioned benefits of SPME, rapid extraction, easy automation, low cost and need for only a small volume of sample are among some of the other advantages which make this technique a green alternative approach to conventional solvent extraction methods. Validation of the SPME fiber as an alternative to LLE for determination of pesticides in surface and ground water samples was already conducted in multiple previous studies $[21,22]$.

As an extension of the SPME method, sensitivity of the technique can be further enhanced by increasing the volume of the coating to achieve lower detection limits. However, sensitivity and extraction time are traded off when this is accomplished by simply increasing the thickness of the fiber [44]. Hence, thin film microextraction (TFME) was developed in 2003 by Bruheim et al. [15] to address this trade-off. This initial development employed a thin sheet of polydimethylsiloxane (PDMS) to be used as a membrane based SPME device. This membrane, provided an increased surface area-to-volume ratio resulting in higher extraction rate and increased sensitivity when compared to the fiber geometry [15]. PDMS/DVB and Carboxen(CAR)/PDMS membranes were also developed to further enhance the extraction efficiency of the pure PDMS 
membrane [45,46]. Recently, Grandy et al. [47] developed a carbon-mesh supported PDMS/DVB membrane as a robust TFME format for on-site sampling by use of portable GC/MS instrumentation. Furthermore, it was demonstrated that these membranes improved on-site method sensitivity for a variety of pesticides in water when compared to a traditional $65 \mu \mathrm{m}$ PDMS/DVB SPME fiber. However, although this membrane geometry has been used for several applications [45-49], a comprehensive evaluation and optimization of TFME from several analytical aspects for the determination of pesticides with a wide range of polarities has not been fully explored. Furthermore, in spite of the many advantages offered by the SPME technique for analysis of water samples, many laboratories are still using LLE as the standard method. Hence, the validation of TFME techniques compared to reference methods approved by the US EPA through inter-laboratory studies can facilitate the adoption of SPME techniques in analytical laboratories for routine analysis of water samples.

It is therefore the intent of this study to validate a TFME method for the analysis of pesticides in surface water samples. The performance achieved by the validated method was then compared to results obtained by LLE as described by an official US EPA method carried out in an accredited analytical laboratory. PDMS/DVB and PDMS/DVB carbon mesh supported membranes were prepared and analysis was performed by use of a thermal desorption unit (TDU) equipped GC/MS instrument. The TFME devices were extensively evaluated from several analytical aspects including stability, lifetime, sensitivity, accuracy and repeatability. Limits of detection in the low ng $\mathrm{L}^{-1}$ range and satisfactory accuracy were obtained by both membranes.

\section{Experimental}




\subsection{Chemicals and reagents}

All stock solutions of pesticide mixtures, including triazines, organophosphorus pesticides (OPPs) and carbamates $\left(100-1000 \mu \mathrm{g} \mathrm{mL}^{-1}\right)$ in acetonitrile (ACN) were purchased from AccuStandard (New Haven, CT, USA). Pure standards of chlorophenols, trifluralin, and methyl parathion were obtained from Sigma-Aldrich (Oakville, ON, Canada). A comprehensive list of the target analytes and their physical-chemical properties is shown in Table S1. Deuterated internal standards (3,5-dichlorophenol-d3, trifluralin-d14, phorate-d10, metolachlor-d6 and diazinon-d10) were obtained from CDN Isotopes (Pointe-Claire, QC, Canada) and 1,000 $\mu \mathrm{g} \mathrm{mL} \mathrm{m}^{-1}$ stock solutions were prepared in ACN. The SYLGARD 184 silicone elastomer mix was acquired from Dow Corning (Midland, MI, U.S.A.). The $5 \mu$ m diameter DVB particles and high density PLOT PDMS were provided by Supelco (Bellefonte, PA, U.S.A). Laboratory reagent water for method development was obtained using a Barnstead/Thermodyne Nanopure ultra-pure water system (Type 1 water grade). Hydrochloric acid and sodium hydroxide were purchased from Sigma-Aldrich (Oakville, ON, Canada). Phosphoric acid and potassium phosphate monobasic were obtained from Fisher Scientific (Ottawa, ON, Canada). Stock solutions of pure standards were prepared in ACN. Working solutions were prepared in ACN by dilution of the stock solutions, which were then used to spike the water samples in preparation of the calibration levels and the fortified samples for optimization and validation.

\subsection{Instrumentation}

An Agilent GC 6890A instrument with a 5973C Series MS detector (Agilent Technologies, CA, U.S.A.) coupled with the GERSTEL cooling injection system 4 (CIS 4) and TDU was used for TFME analysis (GERSTEL, Mülheim an der Ruhr, GE). Automated injections of the membranes were performed using a GERSTEL multipurpose system 2 (MPS2) autosampler which was employed for method development and 
split analyses of the surface water samples at the University of Waterloo. A DB-5.625 capillary column with the length of $30 \mathrm{~m}(0.25 \mathrm{~mm}$ ID, $0.25 \mu \mathrm{m}$ film thickness) was provided by Agilent J\&W (Santa Clara, U.S.A), selected for the chromatographic separation. The carrier gas used was ultra-high purity Helium at 99.999\% (Praxair, Kitchener, Canada), at a flow of $1.2 \mathrm{~mL} / \mathrm{min}$. Temperature programming was used for separation of the compounds with an initial oven temperature set at $50{ }^{\circ} \mathrm{C}$ for 2 minutes, then increased to $220{ }^{\circ} \mathrm{C}$ at $12{ }^{\circ} \mathrm{C} / \mathrm{min}$, followed by an increase to $280{ }^{\circ} \mathrm{C}$ at a $8{ }^{\circ} \mathrm{C} / \mathrm{min}$ and held for 1 minute, for a total run time of 24.7 minutes. Solvent vent/splitless mode was used for desorption and transfer of the compounds to the column.

The TDU desorption temperature program was initially set at $40{ }^{\circ} \mathrm{C}$ for 30 seconds and increased at $700{ }^{\circ} \mathrm{C} / \mathrm{min}$ to the final temperature of 250 ${ }^{\circ} \mathrm{C}$. The pesticides desorbed from the membranes were cryofocused in the $\mathrm{CIS} 4$ at $-80{ }^{\circ} \mathrm{C}$ using liquid nitrogen (Praxair, Kitchener, Canada) and once the desorption was completed, the CIS was heated to $270{ }^{\circ} \mathrm{C}$ at $12{ }^{\circ} \mathrm{C} / \mathrm{s}$ to transfer the analytes to the column. A GERSTEL multipurpose system 2 (MPS2) autosampler was used for automatic injections. Mass spectrometry detection was performed in selected ion monitoring (SIM) mode with electron impact ionization at $70 \mathrm{eV}$. The transfer line temperature was set at $290{ }^{\circ} \mathrm{C}$, the MS source temperature was $230{ }^{\circ} \mathrm{C}$, and the MS quadrupole temperature was $150^{\circ} \mathrm{C}$. (See Table S2 in Supplementary Information). An Elcometer 4340 automatic film applicator (Elcometer Inc., Manchester, UK) was utilized for the preparation of the membranes.

\subsection{Preparation of membranes}


A bar coating method was used for preparation of the PDMS/DVB membranes. Two strategies were applied including support-less and carbonmesh supported PDMS/DVB to prepare the membranes. The unsupported PDMS/DVB membrane was shown to be very flexible and can be easily rolled for insertion into the TDU unit and is therefore very useful when larger membranes need to be prepared to enhance the coating extraction efficiency, which may be useful for the extraction of ultra-trace levels of pollutants from water. On the other hand, the application of a carbonmesh support allowed for the use of much more thermally stable but otherwise fragile PDMS giving a very durable membrane that could be used at higher sample agitation speeds and for on-site untargeted analysis[47]. The detailed preparation procedures for both types of membranes were already reported [46,47]. Briefly, the DVB-PDMS membranes were prepared by dispersing $0.2 \mathrm{~g}$ of DVB particles in $10 \mathrm{~mL}$ of hexane by vortex agitation. After that, $1.0 \mathrm{~g}$ of PDMS elastomer (Dow Corning or high density) was added to mixture followed by sonication. In order to start the cross-linking and condensation of the PDMS, $0.1 \mathrm{~g}$ of curing reagent or $35 \mu \mathrm{L}$ of a catalyst was then added to the mixture respectively. After evaporation of excess hexane under nitrogen, the final mixture was spread in a thin film by a bar coating method and the cross linking process was initiated and accelerated by a thermal curing [46]. For preparation of the PDMS/DVB carbon mesh supported membrane, the same procedure needed to be performed twice to coat both sides of the support material effectively doubling the preparation effort [47]. In order to have a fair comparison, membranes with identical dimension $(2 \mathrm{~cm} \times 0.5 \mathrm{~cm}$, the inner dimensions of the TDU tube heated zone) were compared. Pure PDMS membranes were also made for comparison and evaluation of the particle loaded membranes.

\subsection{Extraction/analysis procedure by TFME-TDU-GC/MS}


During method development, $30 \mathrm{~mL}$ of nanopure water was added to an amber glass vial $(40 \mathrm{~mL})$ and $\mathrm{pH}$ was adjusted to 2.5 ( \pm 0.1 ) by phosphate buffer to achieve higher extraction efficiency for chlorophenol pesticides [21]. 9 mg of $\mathrm{NaCl}$ was added and extraction was performed at $900 \mathrm{rpm}$ for $30 \mathrm{~min}$. The internal standard at $0.5 \mu \mathrm{g} \mathrm{L} \mathrm{L}^{-1}$ was added to the sample for validation. In order to compare the PDMS membrane with the PDMS/DVB membranes, $300 \mathrm{~mL}$ of sample was used to avoid the possibility of exhaustive extraction. After extraction, the membranes were transferred to a TDU tube followed by an automated injection using the Gerstel autosampler. Figure 1 shows the procedure used for extraction and determination of membranes by TDU-GC/MS instrument.

\subsection{Split water samples and application for routine analysis}

Surface water samples were collected from the Grand River at different locations in Waterloo, ON, Canada. A complete characterization of the water samples was performed before the pesticide analyses. Samples were verified as "non-detect" for the selected pesticides, then spiked with the target compounds and internal standards at different concentration levels. The fortified samples were split, coded and submitted to Maxxam Analytics (Maxxam) and the University of Waterloo on a blind basis for non-biased analysis. Three batches of surface water samples (18 samples in total)were collected within 3 months, and analyzed for quantitation of 23 pesticides.

2.6. LLE-GC/MS EPA official method 
An Standards Council of Canada (SCC) accredited method based on LLE and GC/MS was used at Maxxam to analyze the split samples. In summary, $800 \mathrm{~mL}$ of each sample was extracted sequentially with dichloromethane after $\mathrm{pH}$ adjustment to acidic, neutral, and basic conditions, the combined extracts were concentrated, and an aliquot injected onto a GC/MS instrument. Maxxam's standard operating procedure used in this study is based on US EPA method 8270, with three main modifications: SIM mode was used instead of the full scan analysis as specified by the EPA method; liquid extraction was performed in the original glass bottle submitted, whereas the EPA method requires the water sample to be transferred into a separatory funnel prior to extraction; and the amount of dichloromethane used for extraction was $50 \mathrm{~mL}$ instead of the $60 \mathrm{~mL}$ specified in the EPA method. The analyses performed at Maxxam are described in detail in our previous study for the validation of a SPME technique [21].

\section{Results and discussion}

\subsection{Method development}

Parameters that affect the efficiency of the SPME extraction such as desorption temperature, time, stirring rate, extraction time and sample ionic strength were optimized.

3.1.1 Optimization of temperature and desorption time of TDU unit. 
The critical aspect of instrumental design in achieving accurate quantitation is the use of appropriate interfaces to the analytical instrument. They should efficiently transfer all extracted components from the coating to GC/MS for analysis. Hence, a TDU unit was used for desorption of compounds from the membrane, followed by cryofocusing by a CIS system. Desorption time and temperature of the TDU were investigated to assure complete desorption of the extracted pesticides. It is well know from previous studies [47] that substantial TFME membrane bleeding can be observed when high desorption temperature are used. Therefore, temperatures of 250 ${ }^{\circ} \mathrm{C}$ and $270{ }^{\circ} \mathrm{C}$ at different desorption times, namely $5 \mathrm{~min}, 10 \mathrm{~min}$ and $15 \mathrm{~min}$, were investigated. As shown in Figure 2 , nearly the same extraction efficiency was attained for the studied compounds regardless of the tested desorption temperature. Moreover, the amount of bleeding and undesired peaks was significantly lower when $250^{\circ} \mathrm{C}$ was used for both the PDMS/DVB and PDMS/DVB carbon mesh supported membranes. Thus for further experiments $250{ }^{\circ} \mathrm{C}$ was selected as the desorption temperature.

Considering the chemical diversity of the target analytes, desorption time also needed to be optimized. Desorption times of 5 , 10 and 15 minutes were investigated to ensure that all compounds were quantitatively desorbed from the membranes with no/minimum carryover. The results showed that after 5 minutes, all analytes were completely desorbed from the PDMS/DVB and PDMS/DVBcarbon mesh supported membranes as shown in Figure 2. Figure S2 shows the effect of loading the DVB particles into the PDMS membranes, with extraction efficiencies increasing up to 150 times for certain compounds. This enhanced extraction efficiency is also well documented in literature $[22,46]$. Moreover, the addition of DVB particles made the non-supported membrane resilience and 
therefore easier to handle, which subsequently allowed them to be rolled to be inserted into the TDU tube, without sticking to the walls of the TDU tube

\subsubsection{Sample agitation}

The agitation of samples was also investigated to determine its influence on mass transfer of the analytes to the membrane. Flux of analytes in the region outside the boundary layer is directly controlled by agitation whereas in the boundary layer surrounding the SPME device it is controlled by diffusion [44,50]. Furthermore, analyte diffusion through this static boundary layer controls the kinetics of a SPME extraction. It should be noted that the thickness of boundary layer is controlled by agitation, thus a decrease in thickness is assumed to be attained at higher stirring rates with a subsequent increase in the amount of analytes extracted in the preequilibrium regime [44].

In this study, stir rates of 300 rpm, 600 rpm and 900 rpm were investigated. From Figure S3 an increase in the stirring rate leads to an apparent higher extraction efficiency for most of the target pesticides. It also worth mentioning that for the DVB/PDMS carbon mesh supported membranes the improvement in the extraction efficiency is more pronounced between 600 and 900 rpm. This observation may be related to the extra rigidity provided by the carbon mesh support that allows the TFME device to stand higher flow rates without being tilted or bent. This characteristic is particularly useful for on-site analyses applications were the flow of water creeks or 
rivers may be consistent and very fast. In light of these results, a stirring rate of 900 rpm was chosen for further optimization and validation.

\subsubsection{Extraction time profile}

The extraction time using liquid and solid coatings has already been extensively explored in several publications [50,51]. As TFME has a larger surface area-to-volume ratio when compared to traditional SPME [15], it demonstrates a higher extraction rate which is important when pre-equilibrium conditions are used for rapid extractions. Hence, with TFME one has the ability to either decrease extraction time without sacrificing the sensitivity, or maintain a longer extraction time with enhanced sensitivity. This comparison of membranes and fibers has been described previously[15,45,47]. In this study, an extraction time profile was prepared from 5-120 minutes using both membranes. The obtained results, shown in Figure 3, demonstrate that equilibrium was not reached even after 120 minutes of extraction for most of the compounds. As a compromise between sensitivity and method throughput, a 30 minute extraction time was selected for further experiments to have a rapid analysis.

\subsection{Method validation}


The validation of the developed method was carried out under the optimized conditions described in Section 2.4. Blanks containing the selected internal standards were analyzed to determine noise levels for evaluation of the limits of detection (LOD) and limits of quantification (LOQ) defined as signal-to-noise ratio (S/N) equal to 3 and 10, respectively. As shown in Tables 1 and 2 , The PDMS/DVB and PDMS/DVB carbon-mesh supported membranes show high and comparable sensitivity, resulting in low ng $\mathrm{L}^{-1}$ detection limits for most of the compounds studied. LODs in the range of 0.01-0.25 $\mu g \mathrm{~L}^{-1}$ and LOQ between $0.025-0.5 \mu g \mathrm{~L}^{-1}$ for both membranes for the 23 pesticides tested. The linear dynamic range (LDR), also shown in Tables 1 and 2, was evaluated with 1012 calibration points over $0.025-10.0 \mu \mathrm{g} \mathrm{L} \mathrm{L}^{-1}$ with all analytes showing good correlation to signal $\left(\mathrm{R}^{2}>0.99\right)$. With such a broad linear range, weighted linear regression $\left(1 / \mathrm{x}^{2}\right)$ was applied in order to attain the best fitting data and to improve the accuracy of quantitation at lower concentration levels. [52]. It should be noted that un-weighted linear least squares regression provides more weight to higher concentration points leading to poor fitting at lower concentrations. Tables 1 and 2 and summarize the method validation data obtained for both membranes. The detection limits for the developed method for all the studied pesticides not only meet the requirements reported by US EPA [6] but for some compounds, are about 2 orders of magnitude lower than the dictated MCLs. The high extraction efficiency of the membranes is related to the larger volume and surface area of the extraction phase and therefore capacity and kinetics of the membrane extraction phase [15]. It is worth noting that these LODs were achieved with a 30 min (in pre-equilibrium regime) extraction time. LODs could be further decreased by using larger membranes, increasing the extraction time and/or using a larger 
amount of sample, assuming that extraction was neither exhaustive nor negligible. On the other hand, in cases where faster analytical throughput is needed, shorter extraction times could be used, while still meeting or exceeding the US EPA MCLs.

The accuracy of the method was evaluated at three levels of concentration including: $0.06 \mu g \mathrm{~L}^{-1} ; 0.6 \mu \mathrm{g} \mathrm{L}^{-1}$; and $4 \mu \mathrm{g} \mathrm{L}^{-1}$, representing low, medium and high concentration levels within the linear dynamic range. Each concentration level was analyzed in triplicate. As reported in Tables 1 and 2, all compounds showed good accuracy with reasonably good precision as indicated by RSD values in the range of 2-20\%. Given the high stability of the membranes at the chosen experimental conditions [47], long membrane lifetime was also achieved.

\subsection{Analysis of real samples and comparison of TFME and LLE}

Many analytical laboratories use LLE for routine analysis of surface water samples as it is an established and US EPA approved method. The widespread use of LLE is mainly due to its simplicity, i.e., interaction of the sample with an immiscible organic solvent in a separatory funnel. However, this sample extraction method requires relatively large sample volumes to achieve the sensitivity required to meet US EPA MCLs. Larger volumes of organic solvent and the need for specialized waste disposal of these solvents also increase the cost of this technique [21,53].

The throughput for routine analysis can be laborious and tedious. In a previous study [21], an extensive investigation was conducted comparing a fully automated SPME fiber method to LLE. In the present study, TFME was validated, and its performance compared to 
an LLE-based method, namely, US EPA method 8270. This LLE-based method was performed at Maxxam Analytics (Mississauga, ON). Maxxam maintains accreditation through the Standards Council of Canada (SCC) and the United States National Environmental Laboratory Accreditation Program (NELAP) among others.

Three batches of samples were collected over 3 months, with each batch containing 6 samples. Samples were fortified with the target analytes at different concentration levels by a third party then split and submitted to University of Waterloo and Maxxam on a blind basis. While the LLE method required $800 \mathrm{~mL}$ of sample, only $30 \mathrm{~mL}$ was used for the TFME extractions. Even though a lower volume of sample was used for the TFME method, lower detection limits were still achieved in comparison to LLE (Table 3). These lower detection limits were achievable because, unlike LLE, when SPME methods are used all the extracted amount is injected onto the instrument giving higher sample preconcentration. It should also be mentioned that, if the same volume of sample used for LLE were to be used for TFME, even lower detection limits would be attained, as a $30 \mathrm{~mL}$ sample of water is known to be significantly depleted by TFME. Another difference between LLE and TFME lies in the method of quantitation approach, as quantitation of LLE was performed by signal of the instrument since it is considered as an exhaustive technique while for TFME, external calibration was used (based on microextraction methodologies [36].

Table 4 compares the TFME and LLE results of the split sample analyses for the 18 surface water samples. Most of the studied pesticides were not detected by LLE at the sub $\mu \mathrm{g} \mathrm{L}^{-1}$ level. These results indicate that with 414 data points for each method, $90 \%$ of the analytes were quantified by TFME, whereas only 53\% of the compounds were detectable using the LLE method (Table 4). As 
previously mentioned, even with great sensitivity an analytical method is only useful if it can display a reliable degree of analytical accuracy. Hence, to compare the accuracy of the two described methods a blank was first run for each of batch of samples. Accuracy was calculated by dividing the concentration obtained by each method, LLE and TFME, to the true concentration spiked into the samples. In Figure 4, the histograms show accuracy of the results in the ranges of $<50 \%, 50-70 \%, 70-130 \%, 130-150 \%$, and $>150 \%$ with non-detected results being excluded from the percentage. The TFME method was reasonably accurate for the real samples analyzed with approximately $70 \%$ of all results falling within the acceptable range of accuracy, 70-130 \%. This was also in good agreement with the LLE results as the reference method.

\subsection{Environmental impact of the analytical method: a comparison of TFME and LLE}

Greenness of the SPME fiber approach was already investigated and compared to LLE in a previous study by means of calculation of the Eco-scale assessment. [21]. The Eco-Scale was used for evaluation of greenness of the methods [53]. Eco-Scale assessment is based on penalty points assigned to parameters such as reagents, method, energy consumption and waste production in analytical processes which are not favourable with ideal green chemistry. The LLE method has over 40 penalty points, mainly due to usage of large amounts of organic solvent $(100 \mathrm{~mL})$, waste generation and addition of $\mathrm{NaOH}$ and $\mathrm{HCl}$ [21]. In the present study the developed method based on TFME has about 20 penalty points, as only 30-60 $\mu \mathrm{L}$ of ACN was added to water samples, the solvent used for preparation of internal standards and the only source of waste generation is related to the sample itself. By comparison, for LLE, the 
organic solvent represents the extraction phase and it constitutes an essential part of the method that cannot be avoided. Moreover, simultaneous extraction/determination of all pesticides is performed with SPME methods, whereas with LLE, each group of acidic, neutral and basic compounds has to be extracted separately by adjusting $\mathrm{pH}$. Furthermore, the requirement of $800 \mathrm{~mL}$ of sample for the LLE procedure, necessary to improve method sensitivity, leads to the production of a large amount of laboratory waste and increased transportation costs. Therefore, it can be said that while TFME has a similar accuracy to LLE, it has many additional benefits including the need for lower amounts of sample, less complicated handling, propensity to high throughput, automated sampling and much higher sensitivity. Therefore, SPME techniques can be considered as a green and sensitive alternative method to solvent extraction techniques for routine analysis of water samples in contract analytical laboratories.

\section{Conclusion}

A new method based on TFME was developed and validated through an inter-laboratory study of 23 pesticides in surface waters split between laboratories, and submitted on a blind basis. The merits of using membranes were shown from several analytical aspects in comparison to conventional LLE methods. Agreement of the results between TFME and LLE methods demonstrate that TFME can be used for the routine analysis of selected pesticides in surface water samples. TFME was shown to be an accurate method, providing much lower detection limits for many compounds, while eliminating the need for organic solvents and minimizing the amount of sample required. Based on these results, TFME 
might also be considred as an approach for on-site sampling for accurate and rapid quantification of compounds of interest. The improved sensitivity achievable by TFME would offset the lower sensitivity of portable instrumentation.

The goal of our research initiatives is to develop SPME techniques that are appropriate and suitable for use in a contract analytical laboratory environment. For adoption of an analytical technique in industry as a well-accepted method, it is necessary to offer capabilities and advantages that are significantly different from existing approaches and improves the current limitations. While TFME has similar accuracy and precision as LLE (as an official US EPA method) it provides several benefits such as need to small volume of sample, simultaneous analysis of acidic, basic and neutral compounds, rapidness, lower cost and greenness. The data generated in this study support the potential application of TFME techniques in routine, production-oriented analyses.

\section{Acknowledgment}

This research was financially supported by Ontario Research Fund, project number RE-WR-07. The authors thank J. Poole for providing the blind samples. 


\section{References}

[1] P. Quevauviller, A TrAC journey into water-chemical metrology in the European Union, TrAC Trends Anal. Chem. 26 (2007) 52-59.

[2] M.C. Hennion, V. Pichon, D. Barceí, Surface water analysis (trace-organic contaminants) and EC regulations, TrAC - Trends Anal. Chem. 13 (1994) 361-372.

[3] A. Moszczynska, S. Vasiliadis, M. Zanetti, Pesticide researchers face formidable challengesAnnual Meeting Report of the Mediterranean Group of Pesticide Research, Piacenza, Italy, 13 and 14 November 2008, TrAC Trends Anal. Chem. 28 (2009) 135-140.

[4] M.C.R. Alavanja, J. a Hoppin, F. Kamel, Health effects of chronic pesticide exposure: cancer and neurotoxicity., Annu. Rev. Public Health. 25 (2004) 155-197.

[5] US EPA, National primary drinking water regulations, EPA 816-F-09-004, (2009).

[6] US EPA, 2012 Edition of the Drinking Water Standards and Health Advisories, EPA 822-S-12-001, (2012) 1-20.

[7] D. Barcelo, Environmental Protection Agency and other methods for the determination of priority pesticides and their transformation products in water, J. Chromatogr. 643 (1993) 117-1436.

[8] C. Erger, T.C. Schmidt, Disk-based solid-phase extraction analysis of organic substances in water, TrAC Trends Anal. Chem. 61 (2014) 74-82. doi:10.1016/j.trac.2014.05.006.

[9] C. Arthur, J. Pawliszyn, Solid phase microextraction with thermal desorption using fused silica optical fibers, Anal. Chem. 62 (1990) $2145-2148$.

[10] É.A. Souza-Silva, R. Jiang, A. Rodríguez-Lafuente, E. Gionfriddo, J. Pawliszyn, A critical review of the state of the art of solid-phase microextraction of complex matrices I. Environmental analysis, TrAC Trends Anal. Chem. 71 (2015) 224-235.

[11] H. Lord, J. Pawliszyn, Evolution of solid-phase microextraction technology, J. Chromatogr. A. 885 (2000) $153-193$.

[12] H. Piri-moghadam, F. Ahmadi, G.A. Gomez-rios, E. Boyac1, N. Reyes-garces, A. Aghakhani, B. Bojko, J. Pawliszyn, Fast Quantitation of Target Analytes in Small Volumes of Complex Samples by Matrix-Compatible Solid-Phase Microextraction Devices Communications Angewandte, Angew. Chemie Int. Ed. 55 (2016) 7510-7514. doi:10.1002/anie.201601476.

[13] H. Piri-Moghadam, S. Lendor, J. Pawliszyn, Development of a Biocompatible In-Tube Solid Phase Microextraction Device: A Sensitive Approach for Direct Analysis of Single Drops of Complex Matrices, Anal. Chem. 88 (2016) 12188-12195. doi:10.1021/acs.analchem.6b03160.

[14] H. Bagheri, H. Piri-Moghadam, Recent advances in capillary microextraction, TrAC - Trends Anal. Chem. 73 (2015) 64-80. doi:10.1016/j.trac.2015.04.025. 
[15] I. Bruheim, X. Liu, J. Pawliszyn, Thin-Film Microextraction, Anal. Chem. 75 (2003) 1002-1010.

[16] G.A. Gómez-Ríos, J. Pawliszyn, Development of coated blade spray ionization mass spectrometry for the quantitation of target analytes present in complex matrices., Angew. Chem. Int. Ed. Engl. 53 (2014) 14503-14507.

[17] G.A. Gómez-Ríos, J. Pawliszyn, Solid phase microextraction (SPME)-transmission mode (TM) pushes down detection limits in direct analysis in real time (DART)., Chem. Commun. 50 (2014) 12937-12940.

[18] H.L. Lord, Strategies for interfacing solid-phase microextraction with liquid chromatography, J. Chromatogr. A. 1152 (2007) 2-13.

[19] S. Risticevic, Y. Chen, L. Kudlejova, R. Vatinno, B. Baltensperger, J.R. Stuff, D. Hein, J. Pawliszyn, Protocol for the development of automated high-throughput SPME-GC methods for the analysis of volatile and semivolatile constituents in wine samples., Nat. Protoc. 5 (2010) 162-176.

[20] F.S. Mirnaghi, J. Pawliszyn, Reusable solid-phase microextraction coating for direct immersion whole-blood analysis and extracted blood spot sampling coupled with liquid chromatography-tandem mass spectrometry and direct analysis in real time-tandem mass spectrometry, Anal. Chem. 84 (2012) 8301-8309.

[21] A. Rodriguez-Lafuente, H. Piri-Moghadam, H.L. Lord, T. Obal, J. Pawliszyn, Inter-laboratory validation of automated SPME-GC/MS for determination of pesticides in surface and ground water samples: Sensitive and Green Alternative to Liquid Liquid Extraction, Water Qual. Res. J. Canada. (2016).

[22] F. Riazi Kermani, A.-M. Tugulea, J. Hnatiw, V.H. Niri, J. Pawliszyn, Application of automated solid-phase microextraction to determine haloacetonitriles, haloketones, and chloropicrin in Canadian drinking water, Water Qual. Res. J. Canada. 48 (2013) 85-98.

[23] B. Bojko, K. Gorynski, G.A. Gomez-Rios, J.M. Knaak, T. Machuca, V.N. Spetzler, E. Cudjoe, M. Hsin, M. Cypel, M. Selzner, M. Liu, S. Keshavjee, J. Pawliszyn, Solid phase microextraction fills the gap in tissue sampling protocols, Anal. Chim. Acta. 803 (2013) 75-81.

[24] S.M.Z. Hossain, B. Bojko, J. Pawliszyn, Automated SPME-GC-MS monitoring of headspace metabolomic responses of E. coli to biologically active components extracted by the coating, Anal. Chim. Acta. 776 (2013) 41-49.

[25] F. Mousavi, B. Bojko, J. Pawliszyn, Development of high throughput 96-blade solid phase microextraction-liquid chromatrography-mass spectrometry protocol for metabolomics, Anal. Chim. Acta. 892 (2015) 95-104.

[26] H. Piri-Moghadam, F. Ahmadi, J. Pawliszyn, A critical review of solid phase microextraction for analysis of water samples, TrAC Trends Anal. Chem. (2016) 1-11. doi:10.1016/j.trac.2016.05.029.

[27] E.A.S. Silva, J. Pawliszyn, Optimization of Fiber Coating Structure Enables Direct Immersion Solid Phase Microextraction and HighThroughput Determination of Complex Samples, Anal. Chem. 84 (2012) 6933-6938.

[28] É.A. Souza-Silva, E. Gionfriddo, J. Pawliszyn, A critical review of the state of art of solid-phase microextraction of complex matrices. Part II: Food Analysis, TrAC Trends Anal. Chem. 71 (2015) 236-248. 
[29] Erica A. Souza-Silva, E. Gionfriddo, R. Shirey, L. Sidisky, J. Pawliszyn, Methodical evaluation and improvement of matrix compatible PDMS-overcoated coating for direct immersion solid phase microextraction gas chromatography (DI-SPME-GC)-based applications, Anal. Chim. Acta. 920 (2016) 54-62. doi:10.1016/j.aca.2016.03.015.

[30] É.A. Souza-Silva, N. Reyes-Garcés, G.A. Gómez-Ríos, E. Boyaci, B. Bojko, J. Pawliszyn, A critical review of the state of the art of solidphase microextraction of complex matrices iii. bioanalytical and clinical applications, TrAC Trends Anal. Chem. 71 (2015) 249-264.

[31] G. Ouyang, D. Vuckovic, J. Pawliszyn, Nondestructive sampling of living systems using in vivo solid-phase microextraction., Chem. Rev. 111 (2011) 2784-814. doi:10.1021/cr100203t.

[32] B. Bojko, N. Reyes-garcés, V. Bessonneau, K. Goryn, F. Mousavi, E. a S. Silva, J. Pawliszyn, Trends in Analytical Chemistry Solid-phase microextraction in metabolomics, 61 (2014) 168-180.

[33] E. Cudjoe, B. Bojko, I. de Lannoy, V. Saldivia, J. Pawliszyn, Solid-Phase Microextraction: A Complementary In Vivo Sampling Method to Microdialysis, Angew. Chemie Int. Ed. 52 (2013) 12124-12126.

[34] E. Boyac1, Á. Rodríguez-Lafuente, K. Gorynski, F. Mirnaghi, É. a. Souza-Silva, D. Hein, J. Pawliszyn, Sample preparation with solid phase microextraction and exhaustive extraction approaches: Comparison for challenging cases, Anal. Chim. Acta. 873 (2014) 14-30. doi:10.1016/j.aca.2014.12.051.

[35] F.S. Mirnaghi, K. Gory, A. Rodriguez-lafuente, E. Boyac1, B. Bojko, J. Pawliszyn, Microextraction versus exhaustive extraction approaches for simultaneous analysis of compounds in wide range of polarity, J. Chromatogr. A. 1316 (2013) 37-43.

[36] G. Ouyang, J. Pawliszyn, A critical review in calibration methods for solid-phase microextraction, Anal. Chim. Acta. 627 (2008) $184-197$. doi:10.1016/j.aca.2008.08.015.

[37] US EPA (U.S. Environmental Protection Agency), Method 8272, (2007).

[38] International Organization for Standardization ISO 27108:2013: Water quality, (2013).

[39] F. Michel, F. Werres, Y. Chen, B. Shirey, Determination of volatile organic compounds in water by SPME and GC/MS: Validation of new ISO Standard 17943, Supelco/Sigma-Aldrich., (n.d.).

[40] American society for testing and materials ASTM D 6520, (2000).

[41] American Society for Testing and Materials ASTM D 6889, (2003).

[42] American society for testing and materials ASTM D 6438, (2005).

[43] American society for testing and materials ASTM E 2154, (2001).

[44] J. Pawliszyn, Quantitative aspects of SPME, Appl. Solid Phase Microextraction. (1999) Chapter1, pp 3-21.

[45] F. Riazi Kermani, J. Pawliszyn, Sorbent coated glass wool fabric as a thin film microextraction device, Anal. Chem. 84 (2012) $8990-8995$. 
doi:10.1021/ac301861z.

[46] R. Jiang, J. Pawliszyn, Preparation of a Particle Loaded Membrane for Trace Gas Sampling, Anal. Chem. 86 (2014) $403-410$.

[47] J.J. Grandy, E. Boyaci, J. Pawliszyn, Development of a carbon mesh supported thin film microextraction membrane as a means to lower the detection limits of benchtop and portable GC-MS instrumentation, Anal. Chem. (2015) acs.analchem.5b04008.

[48] S.S. Lakade, F. Borrull, K.G. Furton, A. Kabir, N. Fontanals, R.M. Marcé, Comparative study of different fabric phase sorptive extraction sorbents to determine emerging contaminants from environmental water using liquid chromatography-tandem mass spectrometry, Talanta. 144 (2015) 1342-1351. http://linkinghub.elsevier.com/retrieve/pii/S0039914015302290.

[49] R. Kumar, Gaurav, Heena, A.K. Malik, A. Kabir, K.G. Furton, Efficient analysis of selected estrogens using fabric phase sorptive extraction and high performance liquid chromatography-fluorescence detection., J. Chromatogr. A. 1359 (2014) 16-25. http://www.sciencedirect.com/science/article/pii/S0021967314010826.

[50] S. Risticevic, H. Lord, T. Górecki, C.L. Arthur, J. Pawliszyn, Protocol for solid-phase microextraction method development., Nat. Protoc. 5 (2010) 122-139.

[51] H. Lord, J. Pawliszyn, Evolution of solid-phase microextraction technology, J. Chromatogr. A. 885 (2000) $153-193$.

[52] A.M. Almeida, M.M. Castel-Branco, A.C. Falcão, Linear regression for calibration lines revisited: Weighting schemes for bioanalytical methods, J. Chromatogr. B Anal. Technol. Biomed. Life Sci. 774 (2002) 215-222.

[53] A. Gałuszka, Z.M. Migaszewski, P. Konieczka, J. Namieśnik, Analytical Eco-Scale for assessing the greenness of analytical procedures, TrAC - Trends Anal. Chem. 37 (2012) 61-72. doi:10.1016/j.trac.2012.03.013. 


\section{Figure captions}

Figure 1- TFME-GC/MS procedure by PDMS/DVB and PDMS/DVB carbon mesh supported membranes

Figure 2- Optimization of desorption temperature and time of TDU for the studied compounds. PDMS/DVB membrane at $250{ }^{\circ} \mathrm{C}(\mathrm{a})$ and $270{ }^{\circ} \mathrm{C}$ (b); PDMS/DVB carbon mesh supported membranes at $250{ }^{\circ} \mathrm{C}$ (c) and $270{ }^{\circ} \mathrm{C}$ (d). Extraction was performed in $30 \mathrm{~mL}$ of DI water spiked $5 \mathrm{ng} \mathrm{mL} \mathrm{m}^{-1}$, pH adjusted to $2.5( \pm 0.1)$, extraction time: $30 \mathrm{~min}$ and stirring rate of $600 \mathrm{rpm}(\mathrm{n}=3)$

Figure 3- Extraction time profiles of the prepared membranes, Extraction was performed in $30 \mathrm{~mL}$ of DI water spiked $1 \mathrm{ng} \mathrm{mL}^{-1}$, $\mathrm{pH}$ adjusted to $2.5( \pm 1), 10 \% \mathrm{w} / \mathrm{v} \mathrm{NaCl}$ and stirring rate of $900 \mathrm{rpm}$, desorption temperature $250{ }^{\circ} \mathrm{C}$ for 5 minutes.

Figure 4- Accuracy of the TFME and LLE method for analysis 18 surface water sample 
Figure 1

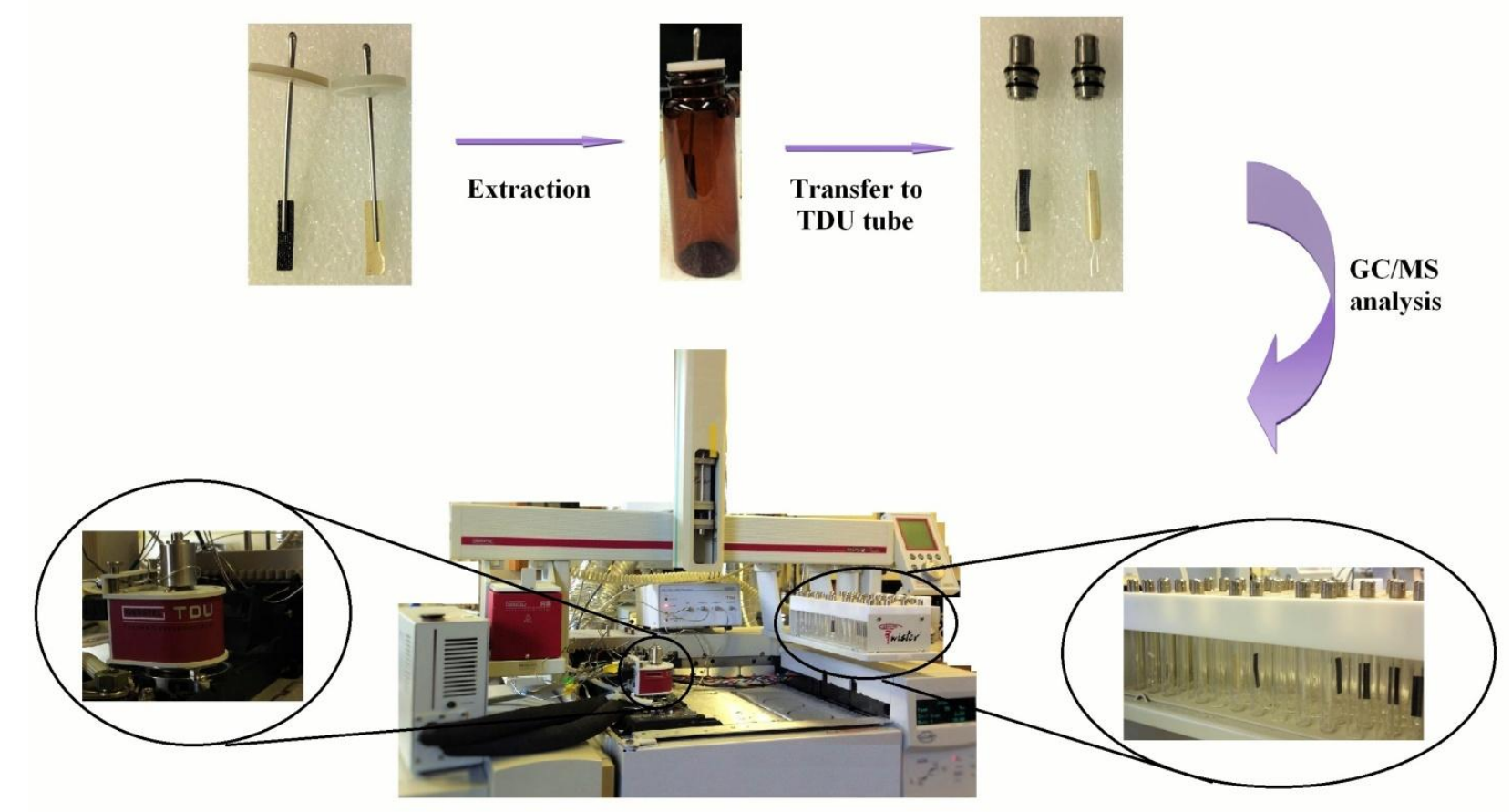


Figure 2

a)

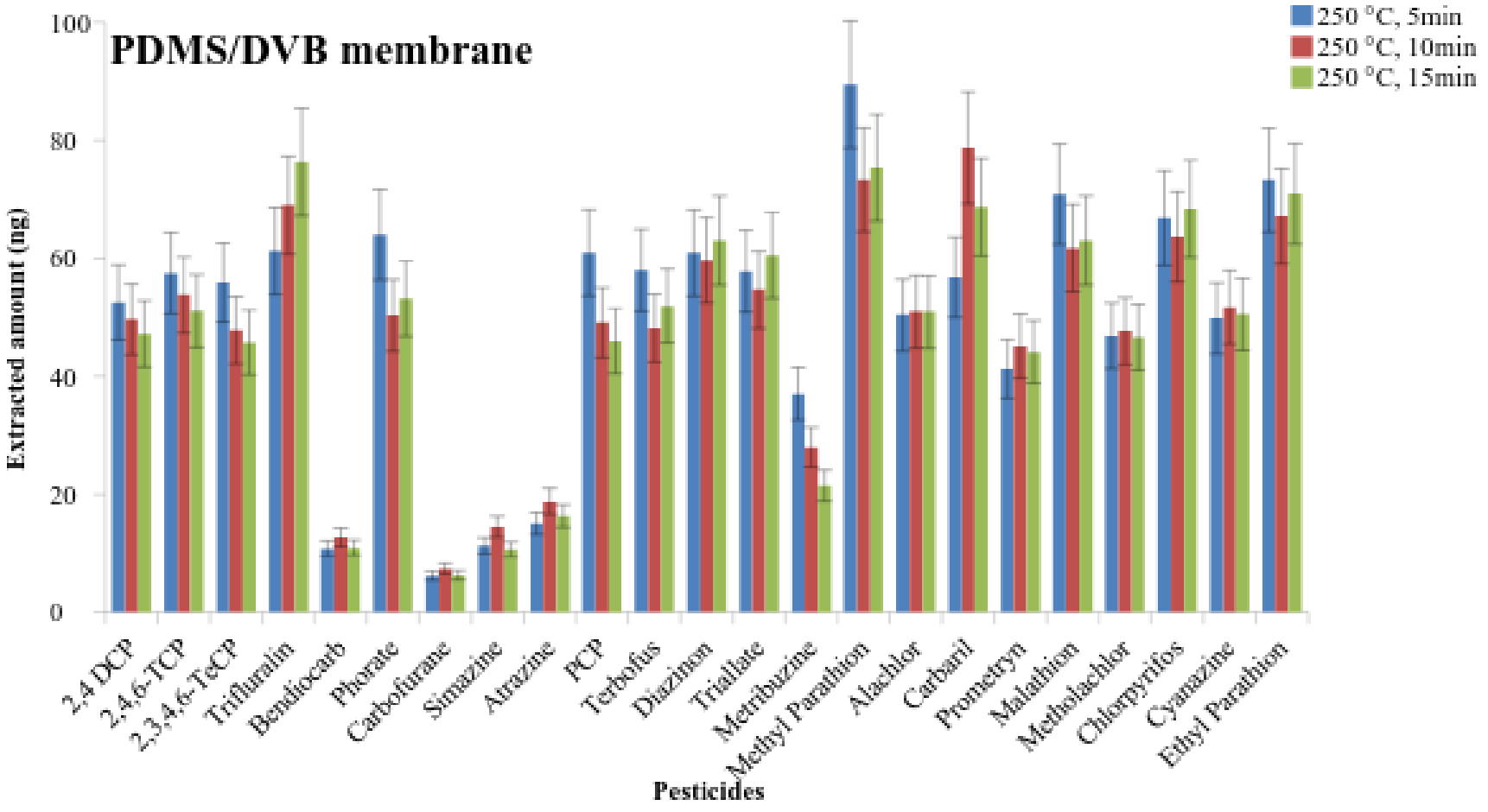

b) 


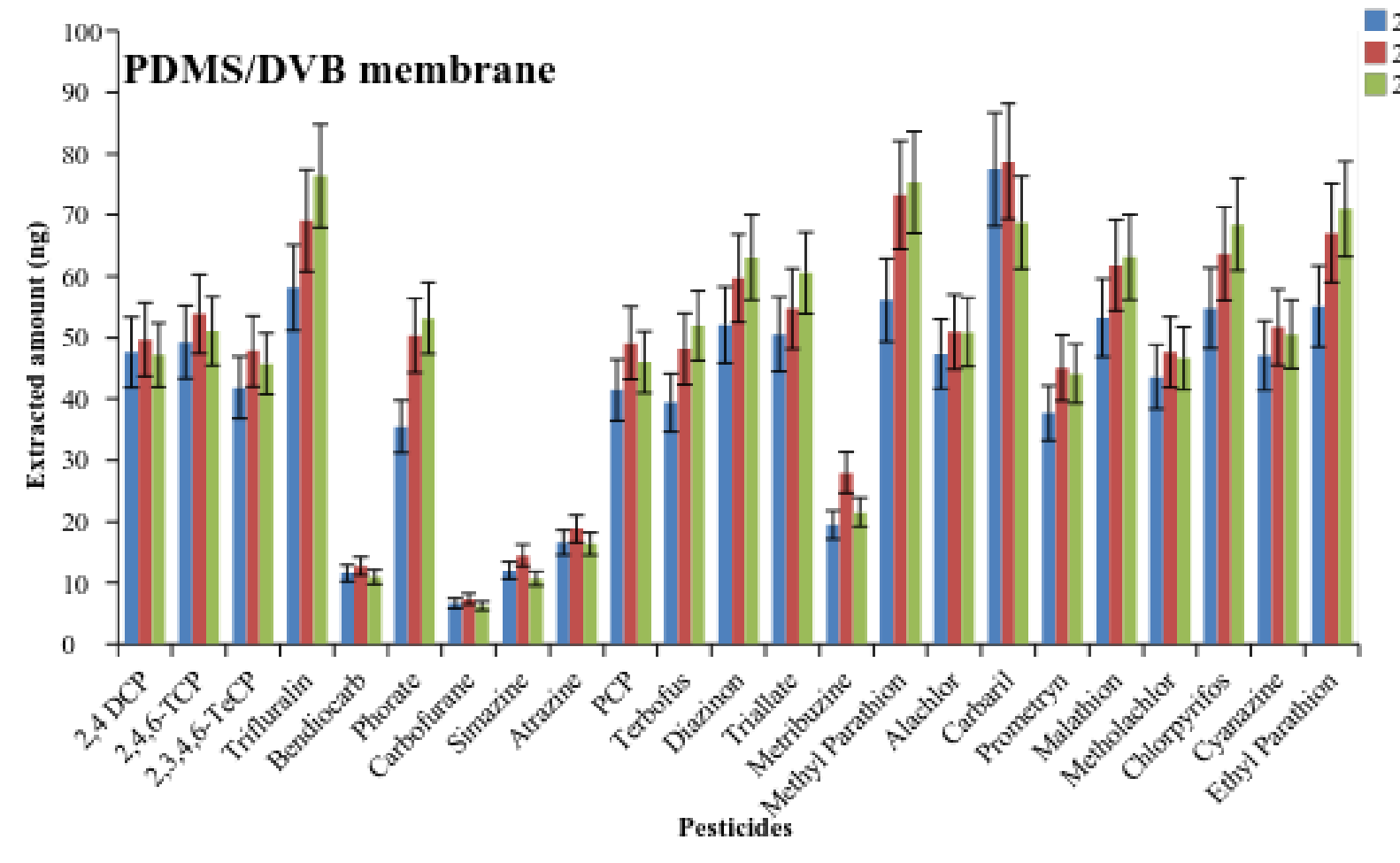

c) 


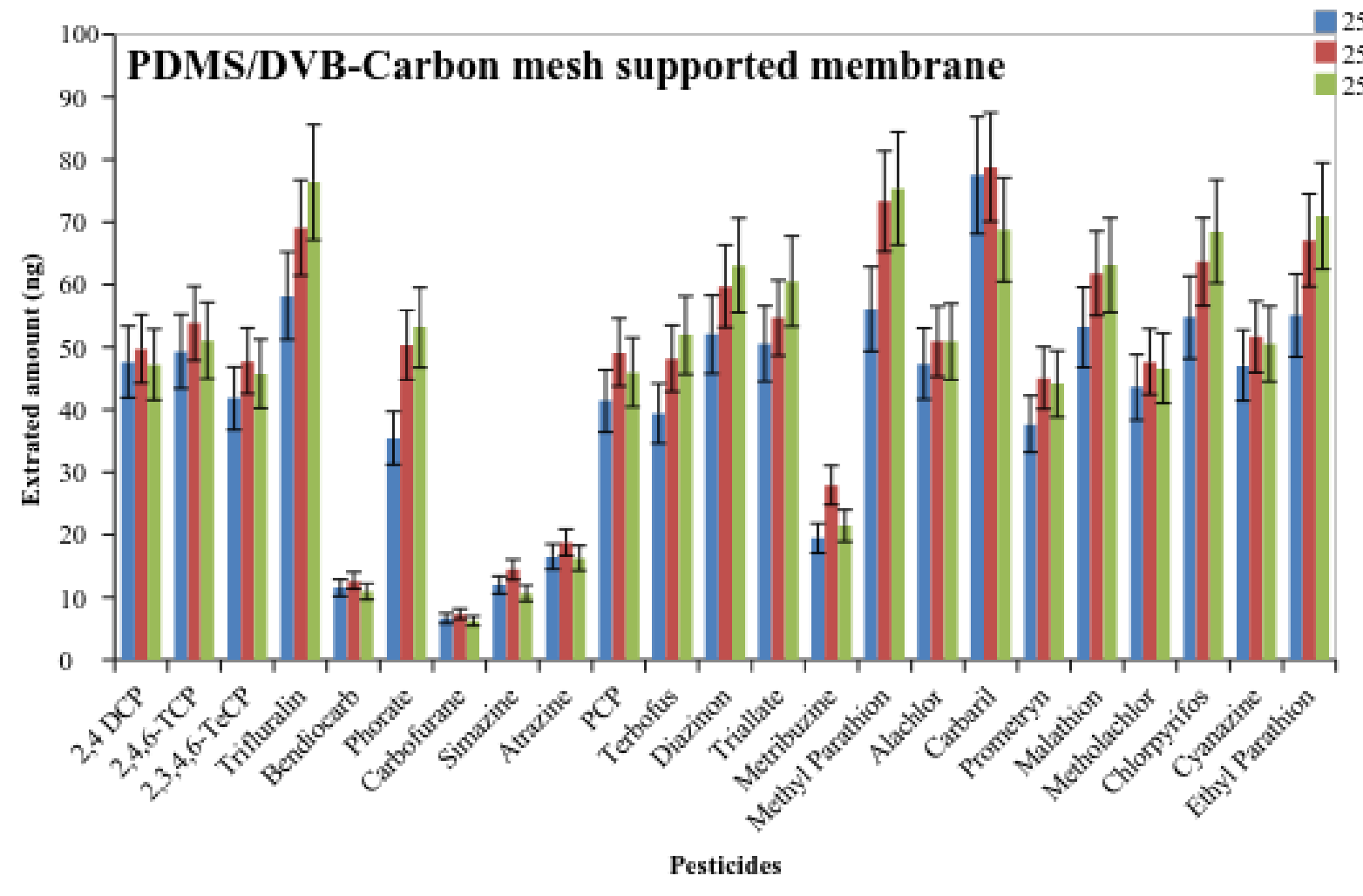

d) 


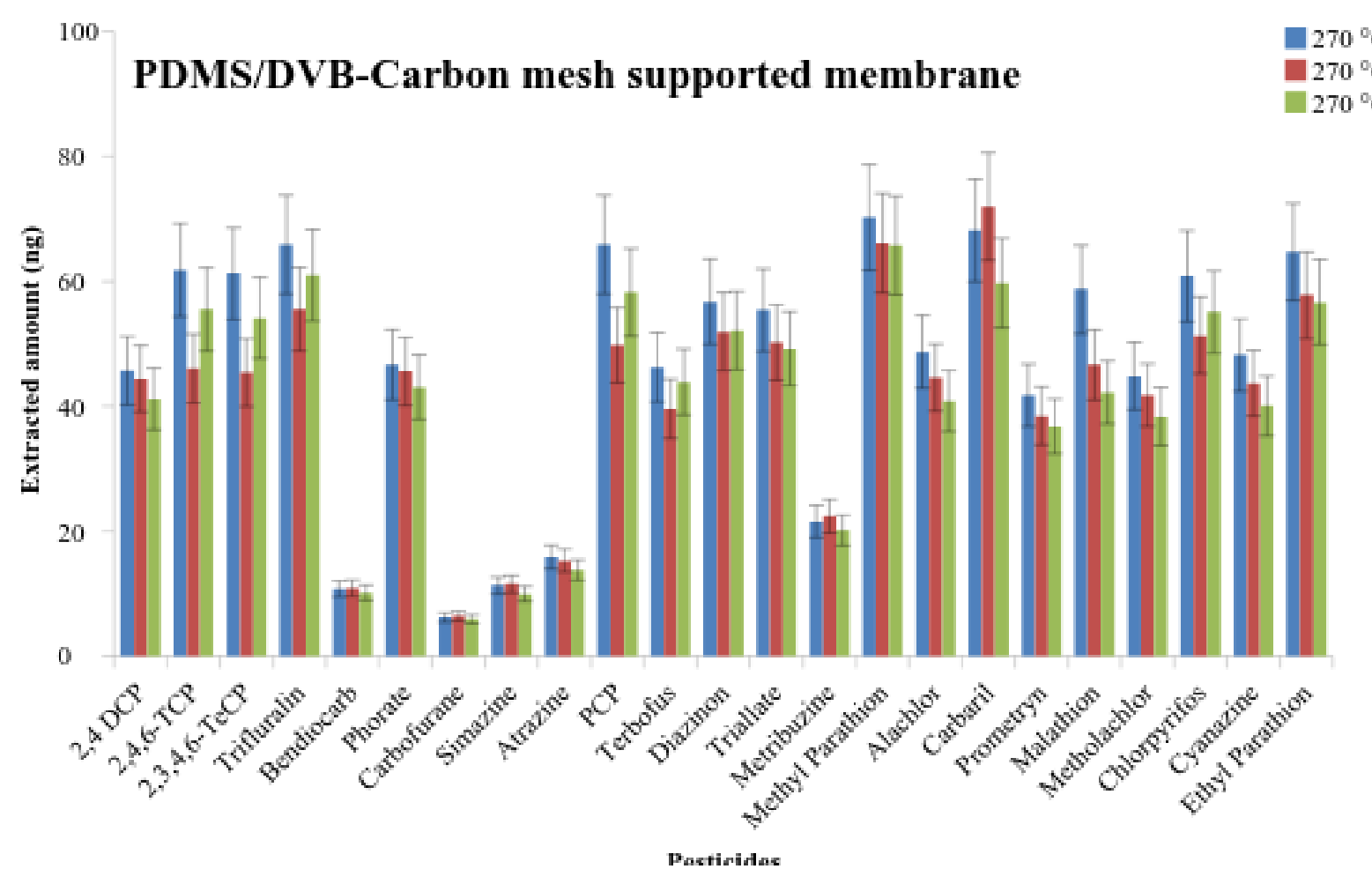

Figure 3

a) 


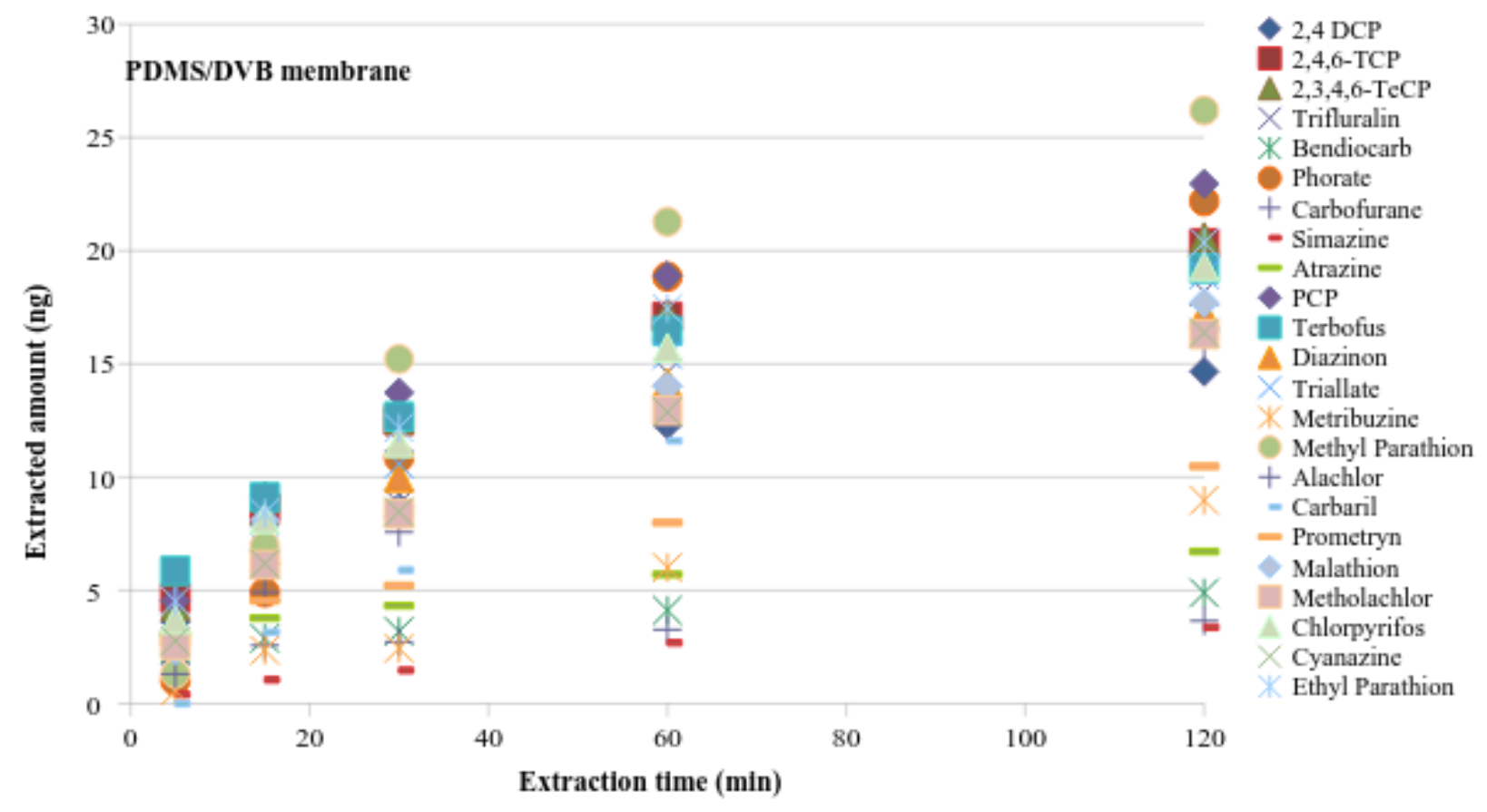

b) 


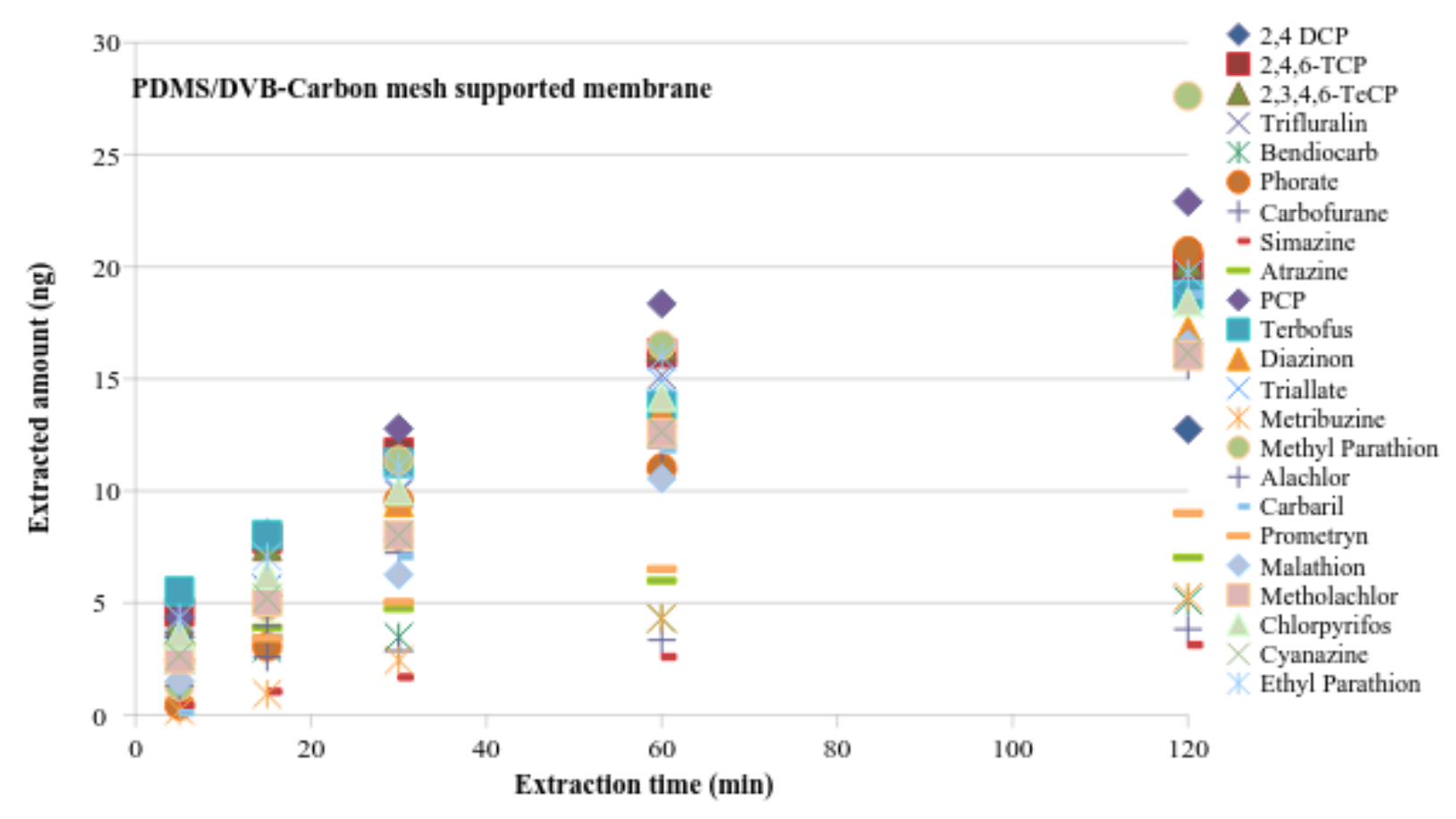

Figure 4. 
口PMS-DVB membrane aPDMS-DVB-carbon mesh supported membrane LLE (US EPA 8270)

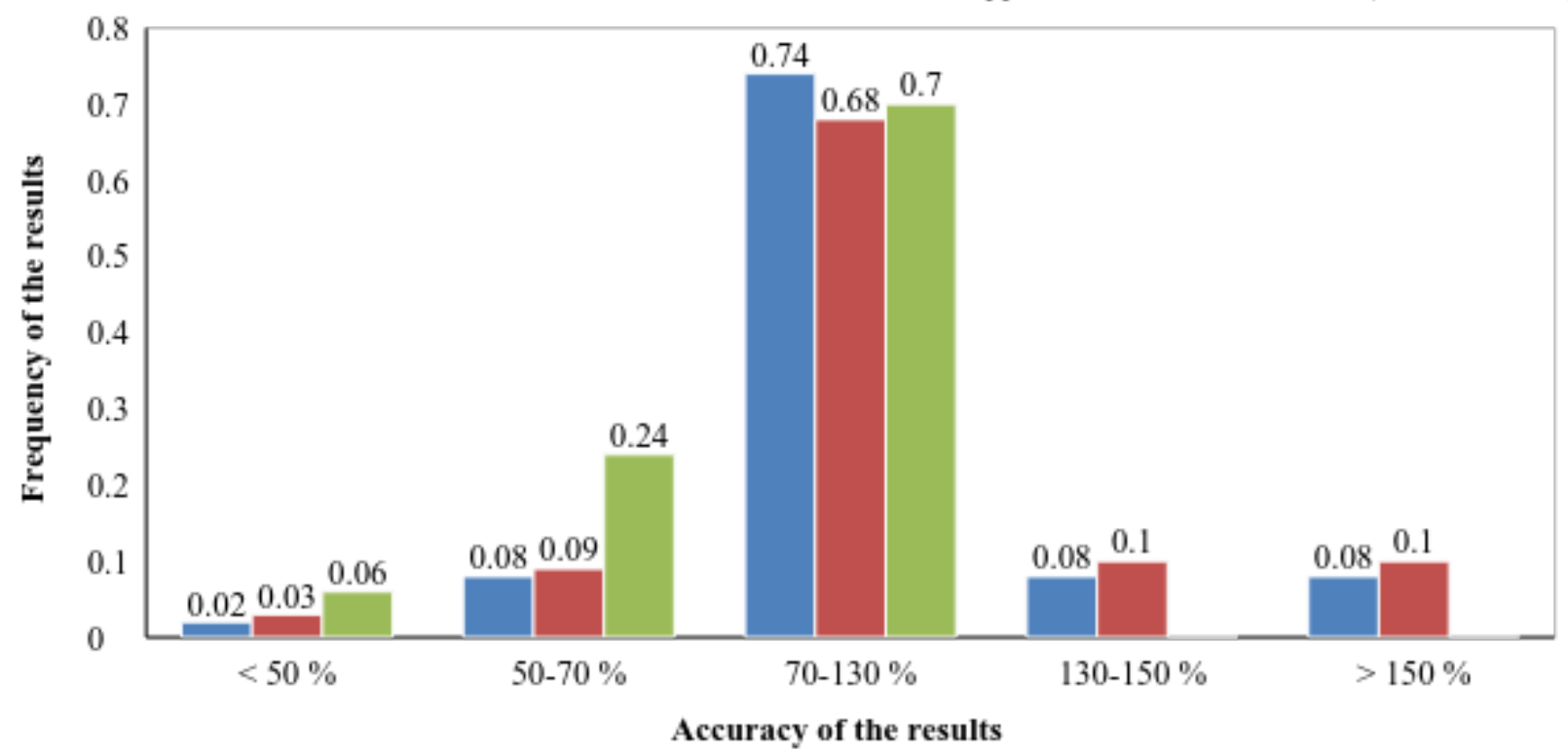


Table 1- Method Validation Data Summary - PDMS-DVB membrane

\begin{tabular}{|c|c|c|c|c|c|c|c|c|c|c|c|c|c|}
\hline \multirow[b]{2}{*}{ Pesticides } & \multirow{2}{*}{$\begin{array}{c}\text { LOD } \\
\left(\mu g L^{-1}\right) \\
(n=3)\end{array}$} & \multirow{2}{*}{$\begin{array}{c}\text { LOQ } \\
\left(\mu g L^{-1}\right) \\
(n=3)\end{array}$} & \multirow{2}{*}{$\begin{array}{c}\text { LDR } \\
\left(\mu g L^{-1}\right) \\
(n=3)\end{array}$} & \multirow[b]{2}{*}{$\mathbf{R}^{2}$} & \multirow[b]{2}{*}{ Slope } & \multirow[b]{2}{*}{ Intercept } & \multirow[b]{2}{*}{ Internal standard } & \multicolumn{3}{|c|}{ Accuracy $(n=3)$} & \multicolumn{3}{|c|}{ Precision (RSD \%) $(n=3)$} \\
\hline & & & & & & & & $\begin{array}{c}0.06 \\
\mu \mathrm{g} \mathrm{L}^{-1}\end{array}$ & $\begin{array}{c}0.60 \\
\mu g L^{-1}\end{array}$ & $\begin{array}{c}4.0 \\
\mu g \mathrm{~L}^{-1}\end{array}$ & $\begin{array}{c}0.06 \\
\mu \mathrm{g} \mathrm{L}^{-1}\end{array}$ & $\begin{array}{c}0.60 \\
\mu g L^{-1}\end{array}$ & $\begin{array}{c}4.0 \\
\mu g L^{-}\end{array}$ \\
\hline $2,4-\mathrm{DCP}$ & 0.025 & 0.050 & $0.050-10.0$ & 0.996 & 0.00220 & -0.0037 & 3,5-DCP-d3 & $90 \%$ & $104 \%$ & $93 \%$ & $9 \%$ & $8 \%$ & $4 \%$ \\
\hline $2,4,6-\mathrm{TCP}$ & 0.010 & 0.025 & $0.025-5.0$ & 0.996 & 0.00186 & 0.0027 & 3,5-DCP-d3 & $94 \%$ & $98 \%$ & $90 \%$ & $5 \%$ & $4 \%$ & $6 \%$ \\
\hline 2,3,4,6-ТеСР & 0.010 & 0.025 & $0.025-5.0$ & 0.991 & 0.00164 & 0.014 & 3,5-DCP-d3 & $87 \%$ & $99 \%$ & $107 \%$ & $8 \%$ & $12 \%$ & $20 \%$ \\
\hline Trifluralin & 0.025 & 0.05 & $0.050-10.0$ & 0.998 & 0.00242 & -0.039 & Trifluralin-d14 & $101 \%$ & $74 \%$ & $88 \%$ & $17 \%$ & $20 \%$ & $17 \%$ \\
\hline Bendiocarb & 0.010 & 0.025 & $0.025-10.0$ & 0.998 & 0.00228 & 0.00023 & 3,5-DCP-d3 & $97 \%$ & $106 \%$ & $96 \%$ & $6 \%$ & $6 \%$ & $3 \%$ \\
\hline Phorate & 0.10 & 0.25 & $0.25-10.0$ & 0.998 & 0.00106 & 0.22 & Phorate-d10 & ND & $70 \%$ & $123 \%$ & ND & $18 \%$ & $10 \%$ \\
\hline Carbofurane & 0.050 & 0.10 & $0.10-10.0$ & 0.996 & 0.00134 & 0.052 & 3,5-DCP-d3 & ND & $123 \%$ & $90 \%$ & ND & $17 \%$ & $7 \%$ \\
\hline Simazine & 0.075 & 0.25 & $0.25-5.0$ & 0.997 & 0.000374 & -0.0043 & Metalachlor-d6 & ND & $89 \%$ & $122 \%$ & ND & $12 \%$ & $8 \%$ \\
\hline Atrazine & 0.075 & 0.25 & $0.25-5.0$ & 0.996 & 0.000975 & 0.057 & Metalachlor-d6 & ND & $101 \%$ & $111 \%$ & ND & $10 \%$ & $5 \%$ \\
\hline PCP & 0.050 & 0.10 & $0.10-5.0$ & 0.991 & 0.00121 & 0.081 & 3,5-DCP-d3 & ND & $115 \%$ & $95 \%$ & ND & $16 \%$ & $9 \%$ \\
\hline Terbufos & 0.10 & 0.25 & $0.25-5.0$ & 0.997 & 0.00469 & 0.43 & Diazinon-d10 & ND & $100 \%$ & $101 \%$ & ND & $12 \%$ & $9 \%$ \\
\hline Diazinon & 0.025 & 0.050 & $0.05-10.0$ & 0.999 & 0.00289 & 0.0065 & Diazinon-d10 & $112 \%$ & $97 \%$ & $117 \%$ & $6 \%$ & $14 \%$ & $3 \%$ \\
\hline Triallate & 0.025 & 0.050 & $0.05-10.0$ & 0.991 & 0.00134 & 0.036 & 3,5-DCP-d3 & $82 \%$ & $123 \%$ & $91 \%$ & $11 \%$ & $22 \%$ & $13 \%$ \\
\hline Metribuzine & 0.050 & 0.10 & $0.10-5.0$ & 0.999 & 0.00187 & -0.052 & Diazinon-d10 & ND & $128 \%$ & $130 \%$ & ND & $3 \%$ & $13 \%$ \\
\hline Methyl parathion & 0.25 & 0.50 & $0.50-5.0$ & 0.987 & 0.00451 & 0.063 & Diazinon-d10 & ND & $85 \%$ & $88 \%$ & ND & $22 \%$ & $12 \%$ \\
\hline Alachlor & 0.025 & 0.050 & $0.050-10.0$ & 0.998 & 0.00128 & -0.0030 & Metalachlor-d6 & $107 \%$ & $100 \%$ & $98 \%$ & $2 \%$ & $4 \%$ & $19 \%$ \\
\hline Carbaryl & 0.050 & 0.10 & $0.10-10.0$ & 0.991 & 0.00179 & 0.12 & 3,5-DCP-d3 & ND & $128 \%$ & $82 \%$ & ND & $17 \%$ & $5 \%$ \\
\hline
\end{tabular}




\begin{tabular}{|c|c|c|c|c|c|c|c|c|c|c|c|c|c|}
\hline Prometryn & 0.025 & 0.075 & $0.075-5.0$ & 0.993 & 0.000690 & 0.032 & Metalachlor-d6 & ND & $129 \%$ & $108 \%$ & ND & $20 \%$ & $4 \%$ \\
\hline Malathion & 0.25 & 0.50 & $0.50-10.0$ & 0.986 & 0.00302 & 0.99 & Diazinon-d10 & ND & $98 \%$ & $103 \%$ & ND & $20 \%$ & $16 \%$ \\
\hline Metalachlor & 0.010 & 0.025 & $0.025-10.0$ & 0.999 & 0.00313 & 0.011 & Metalachlor-d6 & $107 \%$ & $85 \%$ & $115 \%$ & $3 \%$ & $10 \%$ & $20 \%$ \\
\hline Chlorpyrifos & 0.050 & 0.10 & $0.10-2.50$ & 0.993 & 0.00208 & 0.069 & Diazinon-d10 & ND & $87 \%$ & $99 \%$ & ND & $20 \%$ & $2 \%$ \\
\hline Cyanazine & 0.050 & 0.10 & $0.10-10.0$ & 0.999 & 0.000765 & 0.0033 & Metalachlor-d6 & ND & $87 \%$ & $110 \%$ & ND & $9 \%$ & $20 \%$ \\
\hline Ethyl parathion & 0.025 & 0.050 & $0.050-2.50$ & 0.996 & 0.00318 & -0.082 & Diazinon-d10 & $123 \%$ & $101 \%$ & - & $17 \%$ & $14 \%$ & - \\
\hline
\end{tabular}


Table 2- Method Validation Data Summary - PDMS-DVB-carbon mesh supported membrane

\begin{tabular}{|c|c|c|c|c|c|c|c|c|c|c|c|c|c|}
\hline \multirow[b]{2}{*}{ Pesticides } & \multirow{2}{*}{$\begin{array}{c}\text { LOD } \\
\left(\mu g L^{-1}\right) \\
(n=3)\end{array}$} & \multirow{2}{*}{$\begin{array}{c}\text { LOQ } \\
\left(\mu g L^{-1}\right) \\
(n=3)\end{array}$} & \multirow{2}{*}{$\begin{array}{c}\text { LDR } \\
\left(\mu g L^{-1}\right) \\
(n=3)\end{array}$} & \multirow[b]{2}{*}{$\mathbf{R}^{2}$} & \multirow[b]{2}{*}{ Slope } & \multirow[b]{2}{*}{ Intercept } & \multirow[b]{2}{*}{ Internal standard } & \multicolumn{3}{|c|}{ Accuracy $(n=3)$} & \multicolumn{3}{|c|}{ Precision (RSD \%) $(n=3)$} \\
\hline & & & & & & & & $\begin{array}{c}0.06 \\
\mu g L^{-1}\end{array}$ & $\begin{array}{c}0.60 \\
\mu g L^{-1}\end{array}$ & $\begin{array}{c}4.0 \\
\mu g L^{-1}\end{array}$ & $\begin{array}{c}0.06 \\
\mu g^{-1}\end{array}$ & $\begin{array}{c}0.60 \\
\mu \mathrm{g} \mathrm{L}^{-1}\end{array}$ & $\begin{array}{c}4.0 \\
\mu g L^{-1}\end{array}$ \\
\hline 2,4-DCP & 0.050 & 0.10 & $0.10-5.0$ & 0.991 & 0.00198 & -0.068 & 3,5-DCP-d3 & ND & $96 \%$ & $98 \%$ & ND & $20 \%$ & $2 \%$ \\
\hline $2,4,6-\mathrm{TCP}$ & 0.025 & 0.050 & $0.050-5.0$ & 0.992 & 0.00172 & -0.013 & 3,5-DCP-d3 & $112 \%$ & $101 \%$ & $94 \%$ & $10 \%$ & $8 \%$ & $3 \%$ \\
\hline 2,3,4,6-ТеСР & 0.01 & 0.025 & $0.025-10.0$ & 0.994 & 0.00185 & 0.0064 & 3,5-DCP-d3 & $89 \%$ & $104 \%$ & $92 \%$ & $12 \%$ & $10 \%$ & $6 \%$ \\
\hline Trifluralin & 0.025 & 0.050 & $0.050-10.0$ & 0.994 & 0.00239 & -0.0086 & Trifluralin-d14 & $130 \%$ & $115 \%$ & $122 \%$ & $10 \%$ & $17 \%$ & $3 \%$ \\
\hline Bendiocarb & 0.025 & 0.050 & $0.050-5.0$ & 0.993 & 0.00230 & 0.0054 & 3,5-DCP-d3 & $95 \%$ & $110 \%$ & $96 \%$ & $7 \%$ & $13 \%$ & $8 \%$ \\
\hline Phorate & 0.10 & 0.25 & $0.25-5.0$ & 0.999 & 0.000946 & 0.27 & Phorate-d10 & ND & $77 \%$ & $98 \%$ & ND & $15 \%$ & $10 \%$ \\
\hline Carbofurane & 0.050 & 0.10 & $0.10-5.0$ & 0.998 & 0.00163 & 0.070 & 3,5-DCP-d3 & ND & $129 \%$ & $87 \%$ & ND & $17 \%$ & $10 \%$ \\
\hline Simazine & 0.075 & 0.25 & $0.25-5.0$ & 0.998 & 0.000332 & -0.018 & Metalachlor-d6 & ND & $84 \%$ & $127 \%$ & ND & $17 \%$ & $6 \%$ \\
\hline Atrazine & 0.025 & 0.075 & $0.075-5.0$ & 0.999 & 0.000949 & 0.023 & Metalachlor-d6 & ND & $96 \%$ & $120 \%$ & ND & $20 \%$ & $6 \%$ \\
\hline PCP & 0.025 & 0.075 & $0.075-10.0$ & 0.994 & 0.00145 & 0.061 & 3,5-DCP-d3 & $\mathrm{ND}$ & $130 \%$ & $82 \%$ & $\mathrm{ND}$ & $10 \%$ & $17 \%$ \\
\hline Terbufos & 0.10 & 0.25 & $0.25-5.0$ & 0.992 & 0.00387 & 0.59 & Diazinon-d10 & ND & $124 \%$ & $122 \%$ & ND & $19 \%$ & $18 \%$ \\
\hline Diazinon & 0.025 & 0.050 & $0.050-10.0$ & 0.999 & 0.00283 & 0.018 & Diazinon-d10 & $104 \%$ & $92 \%$ & $101 \%$ & $12 \%$ & $20 \%$ & $9 \%$ \\
\hline Triallate & 0.025 & 0.050 & $0.050-10.0$ & 0.989 & 0.00160 & 0.027 & 3,5-DCP-d3 & $92 \%$ & $122 \%$ & $76 \%$ & $20 \%$ & $17 \%$ & $15 \%$ \\
\hline Metribuzine & 0.075 & 0.25 & $0.025-10.0$ & 0.998 & 0.00154 & -0.082 & Diazinon-d10 & ND & $105 \%$ & $122 \%$ & ND & $4 \%$ & $10 \%$ \\
\hline Methyl parathion & 0.25 & 0.50 & $0.50-5.0$ & 0.995 & 0.00386 & -0.12 & Diazinon-d10 & ND & $81 \%$ & $95 \%$ & ND & $4 \%$ & $3 \%$ \\
\hline Alachlor & 0.25 & 0.50 & $0.50-10.0$ & 0.999 & 0.00126 & -0.0043 & Metalachlor-d6 & $115 \%$ & $97 \%$ & $99 \%$ & $2 \%$ & $13 \%$ & $4 \%$ \\
\hline Carbaryl & 0.050 & 0.10 & $0.10-10.0$ & 0.993 & 0.00222 & 0.12 & 3,5-DCP-d3 & ND & $124 \%$ & $71 \%$ & ND & $14 \%$ & $9 \%$ \\
\hline
\end{tabular}




\begin{tabular}{|c|c|c|c|c|c|c|c|c|c|c|c|c|c|}
\hline Prometryn & 0.025 & 0.075 & $0.075-10.0$ & 0.998 & 0.000666 & 0.042 & Metalachlor-d6 & ND & $97 \%$ & $104 \%$ & ND & $8 \%$ & $10 \%$ \\
\hline Malathion & 0.25 & 0.50 & $0.50-10.0$ & 0.997 & 0.00316 & 0.14 & Diazinon-d10 & ND & $113 \%$ & $98 \%$ & ND & $20 \%$ & $19 \%$ \\
\hline Metalachlor & 0.025 & 0.050 & $0.050-10.0$ & 0.997 & 0.00318 & -0.0047 & Metalachlor-d6 & $100 \%$ & $88 \%$ & $109 \%$ & $5 \%$ & $11 \%$ & $4 \%$ \\
\hline Chlorpyrifos & 0.10 & 0.25 & $0.25-10.0$ & 0.998 & 0.00210 & 0.092 & Diazinon-d10 & ND & $126 \%$ & $117 \%$ & ND & $17 \%$ & $19 \%$ \\
\hline Cyanazine & 0.050 & 0.10 & $0.10-10.0$ & 0.997 & 0.000772 & -0.0022 & Metalachlor-d6 & ND & $88 \%$ & $105 \%$ & ND & $11 \%$ & $4 \%$ \\
\hline Ethyl parathion & 0.025 & 0.050 & $0.050-50.0$ & 0.997 & 0.00378 & -0.024 & Diazinon-d10 & $70 \%$ & $86 \%$ & $121 \%$ & $19 \%$ & $20 \%$ & $5 \%$ \\
\hline
\end{tabular}


Table 3. Comparison of Method Detection Limits for TFME and LLE methods

\begin{tabular}{|c|c|c|c|c|}
\hline Pesticides & Units & $\begin{array}{c}\text { TFME } \\
\text { (PDMS/DVB } \\
\text { membrane) }\end{array}$ & $\begin{array}{c}\text { TFME } \\
\text { (PDMS-DVB- } \\
\text { carbon mesh } \\
\text { supported } \\
\text { membrane }\end{array}$ & LLE \\
\hline 2,4-DCP & $\mu g \mathrm{~L}^{-1}$ & 0.025 & 0.050 & 0.25 \\
\hline 2,4,6-ТCР & $\mu g \mathrm{~L}^{-1}$ & 0.010 & 0.025 & 0.50 \\
\hline 2,3,4,6-ТеСР & $\mu g \mathrm{~L}^{-1}$ & 0.010 & 0.01 & 0.50 \\
\hline Trifluralin & $\mu g \mathrm{~L}^{-1}$ & 0.025 & 0.025 & 1.0 \\
\hline Bendiocarb & $\mu g \mathrm{~L}^{-1}$ & 0.010 & 0.025 & 2.0 \\
\hline Phorate & $\mu g \mathrm{~L}^{-1}$ & 0.10 & 0.10 & 0.50 \\
\hline Carbofurane & $\mu g \mathrm{~L}^{-1}$ & 0.050 & 0.050 & 5.0 \\
\hline Simazine & $\mu \mathrm{g} \mathrm{L}^{-1}$ & 0.075 & 0.075 & 1.0 \\
\hline Atrazine & $\mu g \mathrm{~L}^{-1}$ & 0.075 & 0.025 & 0.50 \\
\hline PCP & $\mu \mathrm{g} \mathrm{L}^{-1}$ & 0.050 & 0.025 & 0.50 \\
\hline Terbufos & $\mu g \mathrm{~L}^{-1}$ & 0.10 & 0.10 & 0.50 \\
\hline Diazinon & $\mu \mathrm{g} \mathrm{L}^{-1}$ & 0.025 & 0.025 & 1.0 \\
\hline Triallate & $\mu \mathrm{g} \mathrm{L}^{-1}$ & 0.025 & 0.025 & 1.0 \\
\hline Metribuzine & $\mu g \mathrm{~L}^{-1}$ & 0.050 & 0.075 & 5.0 \\
\hline Methyl parathion & $\mu g \mathrm{~L}^{-1}$ & 0.25 & 0.25 & 1.0 \\
\hline Alachlor & $\mu g \mathrm{~L}^{-1}$ & 0.025 & 0.025 & 0.50 \\
\hline Carbaryl & $\mu g \mathrm{~L}^{-1}$ & 0.050 & 0.050 & 5.0 \\
\hline Prometryn & $\mu g \mathrm{~L}^{-1}$ & 0.025 & 0.025 & 0.25 \\
\hline Malathion & $\mu g \mathrm{~L}^{-1}$ & 0.25 & 0.25 & 5.0 \\
\hline Metalachlor & $\mu g \mathrm{~L}^{-1}$ & 0.010 & 0.025 & 5.0 \\
\hline Chlorpyrifos & $\mu \mathrm{g} \mathrm{L}^{-1}$ & 0.050 & 0.10 & 1.0 \\
\hline Cyanazine & $\mu \mathrm{g} \mathrm{L}^{-1}$ & 0.050 & 0.050 & 1.0 \\
\hline
\end{tabular}


Table 4- Results of blind split analyses of surface water samples by TFME and LLE

\begin{tabular}{|c|c|c|c|c|c|c|c|c|c|c|c|c|c|c|c|c|c|c|}
\hline \multirow{3}{*}{ Pesticides } & \multicolumn{3}{|c|}{$\begin{array}{c}\text { SW 1 } \\
\text { (Fortified at } 0.067 \mu \mathrm{g} \mathrm{L}^{-1} \text { ) }\end{array}$} & \multicolumn{3}{|c|}{$\begin{array}{c}\text { SW } 2 \\
\text { (Fortified at } 0.7 \mu \mathrm{g} \mathrm{L}^{-1} \text { ) }\end{array}$} & \multicolumn{3}{|c|}{$\begin{array}{c}\text { SW 3 } \\
\text { (Fortified at } 0.40 \mu \mathrm{g} \mathrm{L}^{-1} \text { ) }\end{array}$} & \multicolumn{3}{|c|}{$\begin{array}{c}\text { SW 4 } \\
\text { (Fortified at } 1.0 \mu \mathrm{g} \mathrm{L}^{-1} \text { ) }\end{array}$} & \multicolumn{3}{|c|}{$\begin{array}{c}\text { SW } 5 \\
\text { (Fortified at } 3.0 \mu \mathrm{g} \mathrm{L}^{-1} \text { ) }\end{array}$} & \multicolumn{3}{|c|}{$\begin{array}{c}\text { SW 6 } \\
\text { (Fortified at } 8.0 \mu \mathrm{g} \mathrm{L}^{-1} \text { ) }\end{array}$} \\
\hline & \multicolumn{2}{|c|}{ TFME } & & \multicolumn{2}{|c|}{ TFME } & & \multicolumn{2}{|c|}{ TFME } & & \multicolumn{2}{|c|}{ TFME } & & \multicolumn{2}{|c|}{ TFME } & & \multicolumn{2}{|c|}{ TFME } & \\
\hline & $\begin{array}{l}\text { PDMS / } \\
\text { DVB }\end{array}$ & $\begin{array}{l}\text { PDMS / } \\
\text { DVB- } \\
\text { Supp }\end{array}$ & & $\begin{array}{l}\text { PDMS } \\
\text { / DVB }\end{array}$ & $\begin{array}{l}\text { PDMS } \\
\text { / DVB- } \\
\text { Supp }\end{array}$ & & $\begin{array}{l}\text { PDMS } \\
\text { / DVB }\end{array}$ & $\begin{array}{l}\text { PDMS } \\
\text { / DVB- } \\
\text { Supp }\end{array}$ & & $\begin{array}{l}\text { PDMS } \\
\text { / DVB }\end{array}$ & $\begin{array}{l}\text { PDMS } \\
\text { / DVB- } \\
\text { Supp }\end{array}$ & & $\begin{array}{l}\text { PDMS } \\
\text { / DVB }\end{array}$ & $\begin{array}{l}\text { PDMS } \\
\text { / DVB- } \\
\text { Supp }\end{array}$ & & $\begin{array}{l}\text { PDMS } \\
\text { / DVB }\end{array}$ & $\begin{array}{l}\text { PDMS } \\
\text { / DVB- } \\
\text { Supp }\end{array}$ & \\
\hline 2,4-DCP & 0.087 & $<\mathrm{LOQ}$ & ND & 0.73 & 1.10 & 0.37 & 0.44 & 0.38 & ND & 1.1 & 1.4 & 0.49 & 4.9 & 4.1 & 1.6 & 11.0 & 13.0 & 3.9 \\
\hline 2,4,6-ТCP & 0.087 & 0.13 & ND & 0.80 & 1.1 & ND & 0.47 & 0.67 & ND & 1.2 & 1.4 & 0.63 & 4.5 & 4.2 & 2.0 & 11.0 & 10.4 & 5.0 \\
\hline 2,3,4,6-ТеСР & 0.078 & 0.10 & ND & 0.79 & 0.85 & 0.55 & 0.45 & 0.54 & ND & 1.2 & 1.2 & 0.74 & 4.9 & 3.5 & 2.3 & 12.4 & 9.6 & 5.8 \\
\hline Trifluralin & 0.072 & 0.063 & ND & 0.60 & 0.63 & ND & 0.36 & 0.38 & ND & 0.95 & 0.93 & ND & 3.0 & 3.4 & 3.0 & 8.0 & 6.4 & 7.8 \\
\hline Bendiocarb & 0.074 & 0.089 & ND & 0.68 & 0.83 & ND & 0.43 & 0.43 & ND & 1.0 & 1.1 & ND & 4.4 & 3.5 & ND & 10.0 & 5.3 & ND \\
\hline Phorate & ND & ND & ND & 0.58 & 0.53 & ND & $<\mathrm{LOQ}$ & $<\mathrm{LOQ}$ & ND & 0.75 & 0.73 & ND & 3.0 & 3.2 & 1.1 & 8.3 & 9.9 & 3.0 \\
\hline Carbofurane & $<$ LOQ & $<\mathrm{LOQ}$ & ND & 0.88 & 0.94 & ND & 0.54 & 0.56 & ND & 1.3 & 1.2 & ND & 5.0 & 3.7 & ND & 11.3 & 9.1 & 6.8 \\
\hline Simazine & ND & ND & ND & 0.49 & 0.58 & ND & 0.29 & $<\mathrm{LOQ}$ & ND & 0.80 & 0.75 & ND & 2.7 & 3.2 & 1.7 & 6.2 & 6.8 & 4.4 \\
\hline Atrazine & $<$ LOQ & $<\mathrm{LOQ}$ & ND & 0.7 & 0.80 & ND & 0.44 & 0.27 & ND & 1.1 & 1.0 & 0.56 & 2.8 & 3.1 & 2.1 & 6.3 & 6.4 & 5.2 \\
\hline PCP & ND & ND & ND & 0.46 & 0.47 & 0.53 & 0.26 & 0.29 & ND & 0.72 & 0.73 & 0.72 & 2.5 & 2.1 & 2.2 & 6.7 & 7.1 & 5.6 \\
\hline Terbufos & $<$ LOQ & ND & ND & 0.60 & 0.47 & ND & 0.40 & 0.37 & ND & 0.90 & 0.76 & ND & 2.3 & 2.6 & 0.86 & 6.0 & 6.3 & 2.3 \\
\hline Diazinon & 0.078 & 0.073 & ND & 0.70 & 0.72 & ND & 0.42 & 0.42 & ND & 1.0 & 1.0 & ND & 3.3 & 3.2 & 2.2 & 8.4 & 9.1 & 5.7 \\
\hline Triallate & $<\mathrm{LOQ}$ & 0.058 & ND & 0.53 & 0.52 & ND & 0.32 & 0.34 & ND & 0.80 & 0.73 & ND & 2.0 & 2.0 & 3.0 & 5.5 & 6.6 & 7.4 \\
\hline
\end{tabular}




\begin{tabular}{|c|c|c|c|c|c|c|c|c|c|c|c|c|c|c|c|c|c|c|}
\hline Metribuzine & $<\mathrm{LOQ}$ & $<\mathrm{LOQ}$ & ND & 1.10 & 0.14 & ND & 0.63 & 0.48 & ND & 1.4 & 1.3 & ND & 3.7 & 3.5 & ND & 8.8 & 8.0 & 5.3 \\
\hline Methyl parathion & ND & ND & ND & $<\mathrm{LOQ}$ & $<\mathrm{LOQ}$ & ND & $<\mathrm{LOQ}$ & $<\mathrm{LOQ}$ & ND & 0.70 & 1.5 & ND & 1.2 & 1.7 & 2.6 & 6.8 & 7.0 & 7.0 \\
\hline Alachlor & 0.083 & 0.082 & ND & 0.76 & 0.83 & 0.71 & 0.44 & 0.37 & ND & 1.1 & 1.2 & 0.95 & 2.6 & 3.0 & 2.7 & 6.2 & 6.2 & 6.6 \\
\hline Carbaryl & ND & ND & ND & 0.43 & 0.37 & ND & 0.25 & 0.20 & ND & 0.60 & 0.52 & ND & 1.9 & 1.6 & ND & 6.8 & 6.3 & ND \\
\hline Prometryne & $<$ LOQ & $<\mathrm{LOQ}$ & ND & 0.70 & 0.59 & 0.65 & 0.35 & 0.18 & 0.35 & 1.0 & 0.86 & 0.86 & 1.8 & 2.2 & 2.4 & 5.5 & 7.6 & 5.5 \\
\hline Malathion & ND & ND & ND & 0.80 & 1.0 & ND & ND & ND & ND & 0.78 & 1.3 & ND & 3.0 & 2.7 & ND & 8.2 & 6.7 & ND \\
\hline Metalachlor & 0.11 & 0.11 & ND & 0.75 & 0.76 & 0.79 & 0.44 & 0.44 & ND & 1.1 & 1.1 & 1.0 & 3.0 & 2.9 & 2.8 & 7.3 & 7.3 & 7.0 \\
\hline Chlorpyrifos & ND & $<\mathrm{LOQ}$ & ND & 0.35 & 1.3 & ND & 0.19 & 0.90 & ND & 0.48 & 1.9 & ND & 1.5 & 5.0 & 2.8 & 5.6 & 11.6 & 7.1 \\
\hline Cyanazine & 0.12 & 0.13 & ND & 0.71 & 0.72 & ND & 0.43 & 0.42 & ND & 1.0 & 1.0 & ND & 2.7 & 2.6 & 1.8 & 7.0 & 6.7 & 4.7 \\
\hline Ethyl parathion & 0.78 & $<\mathrm{LOQ}$ & ND & 0.65 & 0.50 & ND & 0.38 & 0.25 & ND & 0.94 & 0.77 & ND & 3.6 & 3.0 & 2.9 & 5.4 & 5.9 & 7.5 \\
\hline
\end{tabular}


Table 4 (continued)

\begin{tabular}{|c|c|c|c|c|c|c|c|c|c|c|c|c|c|c|c|c|c|c|}
\hline \multirow{3}{*}{ Pesticides } & \multicolumn{3}{|c|}{$\begin{array}{c}\text { SW 7 } \\
\text { (Fortified at } 2.0 \mu \mathrm{g} \mathrm{L}^{-1} \text { ) }\end{array}$} & \multicolumn{3}{|c|}{$\begin{array}{c}\text { SW 8 } \\
\text { ( Fortified at } 7.5 \mu \mathrm{g} \mathrm{L}^{-1} \text { ) }\end{array}$} & \multicolumn{3}{|c|}{$\begin{array}{c}\text { SW 9 } \\
\text { (Fortified at } 0.75 \mu \mathrm{g} \mathrm{L}^{-1} \text { ) }\end{array}$} & \multicolumn{3}{|c|}{$\begin{array}{c}\text { SW 10 } \\
\text { (Fortified at } 9.0 \mu \mathrm{g} \mathrm{L}^{-1} \text { ) }\end{array}$} & \multicolumn{3}{|c|}{$\begin{array}{c}\text { SW 11 } \\
\text { (Fortified at } 0.87 \mu \mathrm{g} \mathrm{L}^{-1} \text { ) }\end{array}$} & \multicolumn{3}{|c|}{$\begin{array}{c}\text { SW 12 } \\
\text { (Fortified at } 4.5 \mu \mathrm{g} \mathrm{L}^{-1} \text { ) }\end{array}$} \\
\hline & \multicolumn{2}{|c|}{ TFME } & & \multicolumn{2}{|c|}{ TFME } & & \multicolumn{2}{|c|}{ TFME } & & \multicolumn{2}{|c|}{ TFME } & & \multicolumn{2}{|c|}{ TFME } & & \multicolumn{2}{|c|}{ TFME } & \\
\hline & $\begin{array}{c}\text { PDMS / } \\
\text { DVB }\end{array}$ & $\begin{array}{c}\text { PDMS / } \\
\text { DVB- } \\
\text { Supp }\end{array}$ & & $\begin{array}{l}\text { PDMS } \\
\text { / DVB }\end{array}$ & $\begin{array}{l}\text { PDMS } \\
\text { / DVB- } \\
\text { Supp }\end{array}$ & & $\begin{array}{l}\text { PDMS } \\
\text { / DVB }\end{array}$ & $\begin{array}{c}\text { PDMS } \\
\text { / DVB- } \\
\text { Supp }\end{array}$ & & $\begin{array}{l}\text { PDMS } \\
\text { / DVB }\end{array}$ & $\begin{array}{c}\text { PDMS } \\
\text { / DVB- } \\
\text { Supp }\end{array}$ & & $\begin{array}{l}\text { PDMS } \\
\text { / DVB }\end{array}$ & $\begin{array}{c}\text { PDMS } \\
\text { / DVB- } \\
\text { Supp }\end{array}$ & & $\begin{array}{l}\text { PDMS } \\
\text { / DVB }\end{array}$ & $\begin{array}{c}\text { PDMS } \\
\text { / DVB- } \\
\text { Supp }\end{array}$ & \\
\hline $2,4-\mathrm{DCP}$ & 2.5 & 3.0 & 0.86 & 12.6 & 14.7 & 4.0 & 0.83 & 1.1 & 0.36 & 13.0 & 17.7 & 4.2 & 1.1 & 1.3 & 0.33 & 5.6 & 6.3 & 2.7 \\
\hline 2,4,6-ТCP & 2.5 & 2.9 & 1.1 & 10.0 & 14.4 & 4.7 & 0.90 & 1.1 & ND & 10.0 & 16.2 & 5.4 & 1.1 & 1.2 & ND & 5.6 & 6.2 & 3.2 \\
\hline 2,3,4,6-ТеСР & 2.5 & 2.4 & 1.5 & 10.5 & 13.0 & 6.1 & 0.93 & 0.88 & 0.65 & 10.3 & 13.3 & 6.9 & 1.1 & 1.1 & 0.62 & 6.4 & 5.6 & 4.1 \\
\hline Trifluralin & 2.0 & 2.0 & 1.7 & 7.2 & 8.0 & 7.5 . & 0.80 & 0.74 & ND & 8.1 & 8.2 & 8.6 & 0.89 & 0.86 & ND & 4.7 & 4.9 & 5.1 \\
\hline Bendiocarb & 2.1 & 2.3 & ND & 7.5 & 9.5 & 4.0 & 0.80 & 0.75 & ND & 9.6 & 8.7 & 4 & 0.93 & 0.90 & ND & 5.6 & 5.2 & 2.4 \\
\hline Phorate & 2.0 & 2.2 & 0.93 & 11.2 & 12.3 & 4.4 & 0.68 & 0.80 & ND & 11.2 & 13.9 & 4.9 & 0.78 & 0.88 & ND & 5.3 & 5.6 & 2.9 \\
\hline Carbofurane & 2.5 & 2.5 & ND & 11.6 & 10.4 & 7.4 & 0.94 & 0.92 & ND & 12.6 & 10.7 & 8.5 & 1.1 & 1.0 & ND & 5.9 & 4.8 & 5.1 \\
\hline Simazine & 2.3 & 2.3 & 1.1 & 6.2 & 7.8 & 5.1 & 0.86 & 0.75 & ND & 7.6 & 8.3 & 5.7 & 0.98 & 0.92 & ND & 4.7 & 5.8 & 3.3 \\
\hline Atrazine & 2.3 & 2.3 & 1.4 & 6.0 & 7.1 & 5.6 & 0.90 & 0.88 & 0.54 & 7.0 & 7.5 & 6.3 & 1.1 & 1.0 & 0.53 & 4.2 & 5.2 & 3.7 \\
\hline PCP & 1.7 & 1.7 & 1.4 & 8.8 & 8.1 & 5.2 & 0.64 & 0.61 & 0.55 & 9.5 & 8.7 & 5.9 & 0.67 & 0.72 & 0.53 & 4.0 & 3.2 & 3.6 \\
\hline Terbufos & 1.6 & 2.0 & 0.99 & 7.0 & 8.5 & 4.7 & 0.90 & 0.84 & ND & 8.9 & 8.6 & 5.3 & 1.1 & 1.3 & ND & 4.1 & 5.7 & 3.1 \\
\hline Diazinon & 2.1 & 2.2 & 1.2 & 8.3 & 9.2 & 5.5 & 0.75 & 0.77 & ND & 10.0 & 10.3 & 6.2 & 0.94 & 0.94 & ND & 5.2 & 5.2 & 3.8 \\
\hline Triallate & 1.5 & 1.8 & 1.6 & 7.3 & 7.4 & 7.1 & 0.68 & 0.69 & ND & 8.5 & 6.4 & 8.1 & 0.64 & 0.86 & ND & 2.4 & 2.8 & 4.8 \\
\hline Metribuzine & 3.2 & 3.0 & ND & 8.7 & 10.9 & ND & 1.8 & 1.3 & ND & 11.6 & 13.7 & 5.3 & 1.9 & 1.7 & ND & 7.5 & 6.8 & ND \\
\hline Methyl parathion & 1.5 & 1.4 & 1.5 & 3.5 & 4.7 & 6.7 & 1.4 & 0.52 & ND & 8.0 & 6.0 & 7.7 & 1.2 & 1.3 & ND & 3.1 & 2.7 & 4.5 \\
\hline
\end{tabular}




\begin{tabular}{|c|c|c|c|c|c|c|c|c|c|c|c|c|c|c|c|c|c|c|}
\hline Alachlor & 2.4 & 2.5 & 1.8 & 6.3 & 6.3 & 6.2 & 0.95 & 0.93 & 0.75 & 7.8 & 7.3 & 7.1 & 0.93 & 1.1 & 0.74 & 3.6 & 4.3 & 4.3 \\
\hline Carbaryl & 1.2 & 0.98 & ND & 8.0 & 7.5 & 7.8 & 0.46 & 0.49 & ND & 11.0 & 8.6 & 8.7 & 0.48 & 0.48 & ND & 4.0 & 2.3 & 5.2 \\
\hline Prometryne & 2.7 & 2.5 & 1.4 & 8.2 & 8.5 & 6.1 & 1.4 & 1.3 & 0.63 & 10.7 & 9.0 & 6.3 & 1.2 & 1.4 & 0.69 & 5.3 & 5.5 & 4.3 \\
\hline Malathion & 1.4 & 2.7 & ND & 8.7 & 8.0 & 5.2 & ND & 0.33 & ND & 11.5 & 10.0 & 6 & 1.2 & 1.3 & ND & 5.2 & 3.7 & ND \\
\hline Metalachlor & 2.3 & 2.3 & 1.8 & 7.7 & 7.2 & 6.7 & 0.82 & 0.82 & 0.8 & 9.6 & 8.4 & 7.5 & 0.89 & 0.93 & 0.77 & 4.3 & 4.8 & 4.6 \\
\hline Chlorpyrifos & 1.0 & 1.3 & 1.5 & 5.1 & 6.3 & 6.7 & 0.48 & 0.48 & ND & 7.5 & 6.0 & 7.7 & 0.58 & 0.57 & ND & 3.4 & 4.1 & 4.5 \\
\hline Cyanazine & 2.1 & 2.1 & ND & 7.1 & 6.7 & 4.2 & 0.78 & 0.78 & ND & 8.9 & 7.8 & 4.6 & 0.86 & 0.89 & ND & 4.0 & 4.4 & 2.7 \\
\hline Ethyl parathion & 2.4 & 1.9 & 1.6 & 12.8 & 11.2 & 7.2 & 0.81 & 0.64 & ND & 16.6 & 13.8 & 8.3 & 1.0 & 0.78 & ND & 8.1 & 6.0 & 4.9 \\
\hline
\end{tabular}


Table 4 (continued)

\begin{tabular}{|c|c|c|c|c|c|c|c|c|c|c|c|c|c|c|c|c|c|c|}
\hline \multirow{3}{*}{ Pesticides } & \multicolumn{3}{|c|}{$\begin{array}{c}\text { SW 13 } \\
\text { (Fortified at } 0.6 .0 \mathrm{ppb} \text { ) }\end{array}$} & \multicolumn{3}{|c|}{$\begin{array}{c}\text { SW } 14 \\
\text { (Fortified at } 0.40 \mathrm{ppb} \text { ) }\end{array}$} & \multicolumn{3}{|c|}{$\begin{array}{c}\text { SW } 15 \\
\text { (Fortified at } 2.5 \mathrm{ppb} \text { ) }\end{array}$} & \multicolumn{3}{|c|}{$\begin{array}{c}\text { SW } 16 \\
\text { (Fortified at } 0.90 \mathrm{ppb} \text { ) }\end{array}$} & \multicolumn{3}{|c|}{$\begin{array}{c}\text { SW } 17 \\
\text { (Fortified at } 7.5 \mathrm{ppb} \text { ) }\end{array}$} & \multicolumn{3}{|c|}{$\begin{array}{c}\text { SW } 18 \\
\text { (Fortified at } 4.5 \mathrm{ppb} \text { ) }\end{array}$} \\
\hline & \multicolumn{2}{|c|}{ TFME } & & \multicolumn{2}{|c|}{ TFME } & & \multicolumn{2}{|c|}{ TFME } & & \multicolumn{2}{|c|}{ TFME } & & \multicolumn{2}{|c|}{ TFME } & & \multicolumn{2}{|c|}{ TFME } & \\
\hline & $\begin{array}{l}\text { PDMS / } \\
\text { DVB }\end{array}$ & $\begin{array}{l}\text { PDMS / } \\
\text { DVB- } \\
\text { Supp }\end{array}$ & & $\begin{array}{l}\text { PDMS } \\
\text { / DVB }\end{array}$ & $\begin{array}{l}\text { PDMS } \\
\text { / DVB- } \\
\text { Supp }\end{array}$ & & $\begin{array}{l}\text { PDMS } \\
\text { / DVB }\end{array}$ & $\begin{array}{l}\text { PDMS } \\
\text { / DVB- } \\
\text { Supp }\end{array}$ & & $\begin{array}{l}\text { PDMS } \\
\text { / DVB }\end{array}$ & $\begin{array}{l}\text { PDMS } \\
\text { / DVB- } \\
\text { Supp }\end{array}$ & & $\begin{array}{l}\text { PDMS } \\
\text { / DVB }\end{array}$ & $\begin{array}{l}\text { PDMS } \\
\text { / DVB- } \\
\text { Supp }\end{array}$ & & $\begin{array}{l}\text { PDMS } \\
\text { / DVB }\end{array}$ & $\begin{array}{l}\text { PDMS } \\
\text { / DVB- } \\
\text { Supp }\end{array}$ & \\
\hline 2,4-DCP & 0.84 & 0.36 & 0.31 & 0.54 & 0.55 & ND & 4.1 & 3.9 & 1.8 & 1.3 & 1.3 & 0.50 & 8.1 & 14.5 & 4.9 & 7.1 & 6.2 & 2.5 \\
\hline $2,4,6-\mathrm{TCP}$ & 0.82 & 1.1 & ND & 0.54 & 0.58 & ND & 4.0 & 4.1 & 2.0 & 1.1 & 1.4 & 0.57 & 8.5 & 14.9 & 5.5 & 7.1 & 6.5 & 3.0 \\
\hline 2,3,4,6-ТеСР & 0.74 & 0.87 & ND & 0.50 & 0.49 & ND & 4.1 & 3.6 & 2.4 & 1.1 & 1.1 & 0.68 & 9.0 & 12.3 & 6.2 & 7.3 & 5.8 & 3.5 \\
\hline Trifluralin & 0.65 & 0.57 & ND & 0.42 & 0.40 & ND & 3.0 & 3.4 & 2.8 & 0.95 & 1.0 & ND & 8.7 & 7.9 & 7.8 & 4.9 & 5.3 & 4.3 \\
\hline Bendiocarb & 0.51 & 0.35 & ND & 0.33 & 0.34 & ND & 2.6 & 2.6 & ND & 0.68 & 0.80 & ND & 6.2 & 5.7 & ND & 4.3 & 4.2 & ND \\
\hline Phorate & 0.50 & 0.55 & ND & 0.30 & 0.34 & ND & 3.1 & 3.1 & 1.6 & 0.87 & 0.83 & ND & 7.3 & 11.5 & 4.3 & 5.5 & 5.5 & 2.3 \\
\hline Carbofurane & 0.73 & 0.63 & ND & 0.46 & 0.42 & ND & 3.5 & 2.8 & ND & 1.1 & 0.98 & ND & 8.1 & 7.9 & 7.3 & 5.6 & 4.5 & ND \\
\hline Simazine & 0.63 & 0.66 & ND & 0.31 & 0.35 & ND & 3.4 & 2.0 & 1.7 & 0.82 & 0.67 & ND & 7.3 & 8.5 & 5.2 & 5.1 & 6.2 & 3.0 \\
\hline Atrazine & 0.80 & 0.87 & ND & 0.40 & 0.45 & ND & 3.0 & 2.4 & 2.1 & 0.98 & 0.80 & 0.56 & 6.8 & 8.2 & 5.9 & 4.6 & 5.4 & 3.5 \\
\hline PCP & 0.53 & 0.30 & ND & 0.24 & 0.28 & ND & 2.1 & 1.7 & 2.1 & 0.55 & 0.56 & 0.62 & 5.6 & 7.1 & 5.6 & 3.5 & 3.0 & 3.2 \\
\hline Terbufos & 0.78 & 0.54 & ND & 0.47 & 0.45 & ND & 2.8 & 3.1 & 1.5 & 0.88 & 1.0 & ND & 7.9 & 8.1 & 4.1 & 4.2 & 5.2 & 2.2 \\
\hline Diazinon & 0.65 & 0.63 & ND & 0.43 & 0.43 & ND & 3.1 & 3.1 & 2.3 & 0.94 & 0.94 & ND & 7.9 & 8.6 & 6.1 & 5.2 & 5.2 & 3.5 \\
\hline Triallate & 0.82 & 0.49 & ND & 0.42 & 0.37 & ND & 2.2 & 2.1 & 2.9 & 0.56 & 0.64 & ND & 5.9 & 7.5 & 7.7 & 3.4 & 3.0 & 4.4 \\
\hline Metribuzine & 0.96 & 0.91 & ND & 0.64 & 0.62 & ND & 3.4 & 3.0 & ND & 1.4 & 1.1 & ND & 7.7 & 7.3 & 5.2 & 5.6 & 5.9 & ND \\
\hline Methyl parathion & 0.40 & 0.27 & ND & 0.26 & 0.34 & ND & 1.4 & 1.3 & 2.5 & 0.55 & 1.6 & ND & 3.4 & 2.6 & 7.0 & 2.4 & 1.7 & 3.8 \\
\hline
\end{tabular}




\begin{tabular}{|c|c|c|c|c|c|c|c|c|c|c|c|c|c|c|c|c|c|c|}
\hline Alachlor & 0.90 & 0.77 & 0.62 & 0.46 & 0.52 & ND & 2.3 & 2.2 & 2.6 & 0.89 & 0.76 & 0.90 & 6.4 & 7.1 & 6.9 & 3.6 & 4.0 & 3.9 \\
\hline Carbaryl & 0.41 & 0.16 & ND & 0.21 & 0.19 & ND & 1.6 & 1.0 & ND & 0.43 & 0.31 & ND & 4.8 & 5.7 & 6.1 & 3.6 & 1.8 & ND \\
\hline Prometryne & 1.4 & 1.1 & 0.55 & 0.64 & 0.68 & 0.39 & 3.9 & 2.5 & 2.1 & 0.57 & 1.1 & 0.92 & 11.2 & 13.8 & 6.3 & 7.2 & 7.1 & 4.0 \\
\hline Malathion & 0.72 & 0.43 & ND & 0.48 & 0.73 & ND & 1.3 & 2.3 & ND & 0.96 & 0.84 & ND & 5.9 & 5.4 & ND & 3.4 & 2.4 & $\mathrm{ND}$ \\
\hline Metalachlor & 0.65 & 0.66 & 0.62 & 0.38 & 0.43 & ND & 2.5 & 2.2 & 2.7 & 0.98 & 0.78 & 0.90 & 7.6 & 8.3 & 7.2 & 4.5 & 4.4 & 4.1 \\
\hline Chlorpyrifos & 0.29 & 0.31 & ND & 0.18 & 0.81 & ND & 1.6 & 2.2 & 2.7 & 1.3 & 1.1 & ND & 5.9 & 5.5 & 7.3 & 3.0 & 2.5 & 4.1 \\
\hline Cyanazine & 0.62 & 0.63 & ND & 0.40 & 0.50 & ND & 2.2 & 2.0 & 1.2 & 0.97 & 0.77 & ND & 6.9 & 7.7 & 4.4 & 4.0 & 4.0 & 2.6 \\
\hline Ethyl parathion & 0.48 & 0.40 & ND & 0.34 & 0.29 & ND & 3.0 & 2.4 & 2.7 & 1.0 & 0.66 & ND & 9.2 & 8.1 & 7.4 & 6.1 & 4.3 & 4.2 \\
\hline
\end{tabular}

